\title{
SSolar-GOA v1.0: a simple, fast, and accurate Spectral SOLAR radiative transfer model for clear skies
}

\author{
Victoria Eugenia Cachorro, Juan Carlos Antuña-Sanchez, and Ángel Máximo de Frutos \\ Group of Atmospheric Optics, Universidad de Valladolid (GOA-UVa), Valladolid, 47011, Spain
}

Correspondence: Victoria Eugenia Cachorro (chiqui@goa.uva.es)

Received: 1 June 2021 - Discussion started: 22 July 2021

Revised: 22 December 2021 - Accepted: 17 January 2022 - Published: 25 February 2022

\begin{abstract}
The aim of this work is to describe the features of and to validate a simple, fast, accurate, and physically based spectral radiative transfer model in the solar wavelength range under clear skies. The model, named SSolarGOA (the first "S" stands for "spectral"), was developed to evaluate the instantaneous values of spectral solar irradiances at ground level or at a given altitude of the atmosphere. The model requirements are designed based on the simplicity of the analytical expressions for the transmittance functions in order to be easily replicated and applied by a wide community of users for many different applications (atmospheric and environmental research studies, satellite remote sensing, solar energy, agronomy and forestry, ecology, and others). Although spectral, the model runs quickly and has sufficient accuracy for the evaluation of solar irradiances with a spectral resolution of $1-10 \mathrm{~nm}$. The model assumes a single mixed molecule-aerosol scattering layer where the original Ambartsumian method of "adding layers" in a onedimensional medium is applied, obtaining a parameterized expression for the total transmittance of scattering. Absorption by the different atmospheric gases follows "band model" parameterized expressions. The input parameters must be realistic and easily available since the spectral aerosol optical depth (AOD) is the main driver of the model. The validation of the SSolar-GOA model has been carried out through comparison with simulated irradiance data from the libRadtran package and with direct and global spectra measured by spectroradiometers. Thousands of spectra under clear skies have been compared for different atmospheric conditions and solar zenith angles (SZA). The SSolar-GOA is validated by a quantitative comparison with libRadtran, showing that it underestimates direct normal, global, and diffuse spectral components with relative differences of $+1 \%$ (RMSE \% $=4.6-$
\end{abstract}

8), $+3 \%(\mathrm{RMSE} \%=5.3-8)$, and $8 \%(\mathrm{RMSE} \%=9.3-9.6)$, respectively, when the SZA varies from 6 to $60^{\circ}$. Compared with the measured irradiance data of the LI-1800 and ASD spectroradiometers, the relative differences of direct normal and global components are within the overall experimental error, about $\pm 2 \%-12 \%$ (RMSE $\%=5-8.3$ ), with underestimated or overestimated values. The diffuse component presents the highest degree of relative difference that can reach $\pm 20 \%-30 \%$ and RMSE of $25 \%-50 \%$. The relative differences depend strongly on the spectral solar region analysed and the SZA, but the high values of RMSE are due to the artifice generated by the different spectral resolution of the absorption coefficients of both models. Model approach errors combined with calibration instrument errors may explain the observed differences. The SSolar-GOA v1.0 is implemented in Python and open-source licensing.

\section{Introduction}

Solar radiation is the primary energy source of the Earthatmosphere system. It is the driver of the most important mechanisms of the atmosphere-climate system, mainly through radiation energy balance and the greenhouse effect (Goody, 1964; Houghton, 2002; Wild et al., 2013). Solar radiation governs thermal and hydrological conditions which are fundamental for life on Earth, as well as the environment, ecology, agriculture, forestry, etc. Today, solar radiation is also of great importance in other areas, i.e. solar energy, urban building design, engineering applications. Therefore, measurements and modelling of solar radiation are essential in many fields. The evaluation of global, direct, and diffuse components is of particular importance. Earth sur- 
face solar radiation measurements are currently carried out using broadband radiometers at meteorological stations from different national weather services or more specific worldwide radiometric networks, such as the Global Radiation and Aerosols (GRAD, 2021) of the ESRL Global Monitoring Laboratory-NOAA, or the National Solar Radiation Database (NSRDB-NREL, 2021). The diversity of solar radiation networks with different objectives and applications presents variable data quality; only specific networks can guarantee the quality of solar radiation data, such as the BSRN (BSRN: Baseline Surface Radiation Network, 2021), to ensure climatological trend studies or precise values for global balance in the Earth system (Wild et al., 2013; Wild, 2009).

This work focuses on spectral solar surface radiation measurements which give continuous spectra for a wide spectral range (i.e. UV $(\sim 300-400 \mathrm{~nm})$, visible $(\sim 400-700 \mathrm{~nm})$, near-infrared $(\sim 700-1000 \mathrm{~nm})$ and the entire solar range $(\sim 300-3000 \mathrm{~nm}))$ under clear skies. Broadband solar radiation data are very abundant, but spectral solar radiation measurements are comparatively scarce. Generally, wellestablished networks are not available for this purpose, and most of the known spectral solar data are restricted to specific research campaigns, although some research centres and research groups have recorded important databases: NREL Spectral Solar Radiation Data Base (2021); GOA-UVA solar radiation (2021); WOUDC, the Ultraviolet Radiation Data center (2021). The main reason for this is that the instruments for these measurements - the spectroradiometers - are more complex electro-optical systems for field measurements, and calibration procedures and maintenance are difficult to perform routinely in a non-operational network. One example is the MFRSR (Hodges, 1993) USA network, which provides spectral radiation data but only at specific wavelengths. Today, well-known detection systems based on silicon photodiode (CCD) arrays are part of modern spectroradiometers, which are increasingly used, facilitating spectral measurements.

However, it is possible to find many references in the literature which are focused on instruments, measurements, and modelling of surface spectral solar radiation (Leckner, 1978; Koepke and Quenzel, 1978; Bird, 1984; Cachorro et al., 1985, 1987a, b, c, 1997; Bird and Riordan, 1986; Riordan et al., 1989; Gueymard, 1995, 2001, 2005, 2008, 2019; Utrillas et al., 1998, 2000; Kiedron et al., 1999; Mlawer et al., 2000; Martínez-Lozano et al., 2003; Bais et al., 2005; Michalsky et al., 2006; Habte et al., 2014; Egli et al., 2016; Mlawer and Turner, 2016). These types of surface spectral solar measurements are also extensively used to retrieve the content and properties of different atmospheric components such as water vapour, ozone, aerosols, etc. (Cachorro et al., 1986, 1996, 1998, 2000a, b; Martiìnez-Lozano et al., 1998; Carlund et al., 2003; Vergaz et al., 2005; Toledano et al., 2006; Estellés et al., 2006). Although atmosphere-climate sciences and solar energy are the most important fields where spectral solar radiation data are required, other fields also ap- ply them, as can be seen in a recent publication of Gueymard (2019). Spectral solar radiation data are currently in great demand by the photovoltaic (PV) community for solar power due to the extensive use of PV modules whose performance must be evaluated (Norton et al., 2015; Amillo et al., 2015; Sengupta et al., 2018).

Spectral solar radiation measurements have been carried out by the "Grupo de Optica Atmosférica" of the "Universidad de Valladolid (GOA-UVA)" for more than two decades in conjunction with the development and use of different solar radiation models, as part of its routine work in atmospheric studies and in other related areas (Cachorro et al., 1985, 1987a, b, c, 1997, 1998; Vergaz et al., 2005; Toledano et al., 2006; Berjón et al., 2013). The modelling of these measurements is the main aim of this work: to set up and to validate a simple, fast, and accurate spectral solar radiative transfer model covering the entire solar range. The model is especially suited for the measurements of spectroradiometers working at low to medium spectral resolution (i.e. 1-10 nm). The idea is to provide a radiation spectral model to a wide community of users; thus, the model must be theoretically simple and easy to use and replicate. Fast calculations of the model are devoted especially for network-routine data of high time resolution, long data series analysis or reconstruction, satellite solar radiation estimation, and applications in solar energy or other areas. The SSolar-GOA is now at v1.0, implemented in Python and open-source licensing.

The paper is structured as follows: Sect. 2 briefly describes the characteristics of the two spectroradiometers employed to perform the solar spectral measurements and gives a general theoretical background on the context of solar radiation modelling. Section 3 describes the SSolar-GOA model. Section 4 presents the results of validation of the SSolar-GOA model by the comparison with libRadtran package (libRadtran User's Guide, 2015, 2020), which was used as the benchmark, and also by the comparison with experimental solar spectral radiation data. Conclusions and recommendations are also discussed in the last section.

\section{Material and methodology}

\subsection{Instrumentation and measurements}

The experimental measurements of solar spectral irradiance for the validation process of the SSolar-GOA model were taken using two commercial spectroradiometers. The first spectroradiometer used was the LI- 1800 model from Li-COR Biosciences (LI-COR, 1989), which covers the 300-1100 nm spectral range and is based on monochromator holographic grating of 800 grooves $\mathrm{mm}^{-1}$ with a nominal FWHM (full width at half-maximum) or spectral resolution of $6 \mathrm{~nm}$ (according to Vergaz et al., 2000, the FWHM measured at our Laboratory was $6.25 \pm 0.07$ at $632.8 \mathrm{~nm} \mathrm{He}-\mathrm{Ne}$ laser wavelength). The scanning system of LI- 1800 takes about $40 \mathrm{~s}$ to 
measure a solar spectrum. The software of the system allows variable wavelength sampling, but currently $1 \mathrm{~nm}$ and also a programmable time are used for the measurement of global solar radiation spectra (or the direct component with a solar tracker). The LI-1800 is manufactured with a Remote Cosine Receptor for global solar irradiance measurements, but different fore-optic devices designed by the GOA Group allow for direct normal irradiance and reflected solar irradiance measurements (Durán, 1997).

The other spectroradiometer used was the FieldSpec Pro (hereafter, ASD), a general purpose portable spectroradiometer developed by ASD Inc. (ASD Full Range, Portable Spectrometers \& Spectroradiometers | Malvern Panalytical, 2021; Milton et al., 2009; Goetz, 2012; Hannula et al., 2020). This spectroradiometer covers the $350-2500 \mathrm{~nm}$ shortwave range and is composed of three spectrometers: the VNIR from 350$1050 \mathrm{~nm}$ is composed of a 512-channel silicon photodiode (CCD) array overlaid with an order separation filter, a second scanning spectrometer (SWIR-1) from 1050 to $1800 \mathrm{~nm}$, and a third scanning spectrometer (SWIR-2) to $2500 \mathrm{~nm}$. Each SWIR consists of a concave holographic grating and a single thermoelectric cooled indium gallium arsenide (InGaAs) detector. Each grating is mounted on a common shaft which oscillates at $100 \mathrm{~ms}$ per scan, thus providing their spectra in a few seconds and the CCD array makes it simultaneously in the VNIR spectral range. The spectral resolution of the ASD is different for each of the three spectrometers: the VNIR has approximately $3 \mathrm{~nm}$ of spectral resolution at around $700 \mathrm{~nm}$, and the SWIRs have about $10-12 \mathrm{~nm}$.

The ASD system is provided with specific fore-optical accessories for field radiance and irradiance measurements of different FOVs (fields of view of 1,3 , and $8^{\circ}$ ), and a remote cosine receptor is used for global irradiance and for measuring full-hemisphere albedo or reflectance spectra. Light collection is achieved through a bundle of optical fibre. For direct normal irradiance measurements, the earlier fore-optic accessories used for radiance measurements cannot be used. This is because each tube is provided with a lens which focuses the radiation over the optical fibre, and due to the high energy of the normal direct irradiance, this may damage the fibre. Thus, a new tube collimator was designed by the GOA Group which can be used with the ASD.

Calibration details, associated errors, and measurements of the LI-1800 for both direct and global irradiances were discussed in Vergaz (2001), Martínez-Lozano et al. (2003), Vergaz et al. (2005), and Estellés et al. (2006). As a general feature, the LI-1800 presents an experimental error of about $5 \%$ in the $340-1100 \mathrm{~nm}$ spectral range while the instrument itself has proven to be durable and have a long-lasting calibration. The ASD solar irradiance measurements have similar errors to LI-1800. Despite the advantage of registering near-instantaneous spectra and automatic optimization, the latter results in variable integration times and gains for one measured spectrum over another, that being a drawback in the data processing. This requires special care and attention for field solar irradiance measurements, and normally postprocessing is necessary since frequent saturation is observed in the spectra, which is not always avoidable. In both spectroradiometers, the LI-1800 and ASD diffuse solar irradiances are derived from the difference between near-simultaneous measured spectra of global and direct normal irradiances.

\subsection{General theoretical background for solar spectral irradiance models at surface level}

The global solar spectral irradiance $\mathrm{GHI}(\mathrm{SZA}, \lambda)$ at ground level over a horizontal surface and for a given Sun position (specified by the solar zenith angle, SZA) can be expressed as the sum of its direct normal component (DNI(SZA, $\lambda$ )) projected onto the horizontal surface (hence multiplied by $\cos (\mathrm{SZA}))$, plus the horizontal diffuse irradiance component DIF(SZA, $\lambda$ ), also dependent on the SZA.

$$
\begin{aligned}
\mathrm{GHI}(\mathrm{SZA}, \lambda) & =\mathrm{DNI}(\mathrm{SZA}, \lambda) \cos (\mathrm{SZA}) \\
& +\mathrm{DIF}(\mathrm{SZA}, \lambda)
\end{aligned}
$$

Although the wavelength is explicit in the above Eq. (1), it should be noted that it is valid for both spectral and integrated irradiance values (in this case removing $\lambda$ and considering the integration over the entire solar range). These quantities are usually expressed in the units of $\mathrm{W} \mathrm{m}^{-2} \mu^{-1}$ $\left(\mathrm{W} \mathrm{m}^{-2} \mathrm{~nm}^{-1}\right.$ ) for spectral irradiance values, and $\mathrm{W} \mathrm{m}^{-2}$ for integrated irradiance values. There is not a unified nomenclature to designate the three components of solar radiation at surface level (global or total horizontal solar irradiance (GHI) is also called shortwave downwelling solar irradiance (SWD), shortwave surface irradiance (SSI), surface total solar flux, etc.). Therefore, Eq. (1) incorporates the most recent and most widely used names in the solar energy community for these irradiances.

If we divide these irradiances by the irradiance at the top of the atmosphere (the extraterrestrial irradiance, $F_{o}$, multiplied by the corresponding correction of the Earth-Sun distance $(D)$ projected over the horizontal plane, $D \cdot F_{o} \cos (\mathrm{SZA})$ ), the corresponding atmospheric transmittances at surface level for the above three components are obtained: global transmittance $T_{\mathrm{GHI}}(\mathrm{SZA}, \lambda)$, normal direct transmittance $T_{\mathrm{DNI}}(\mathrm{SZA}$, $\lambda)$, and diffuse transmittance $t_{\mathrm{DIF}}(\mathrm{SZA}, \lambda)$.

$T_{\mathrm{GHI}}(\mathrm{SZA}, \lambda)=T_{\mathrm{DNI}}(\mathrm{SZA}, \lambda)+t_{\mathrm{DIF}}(\mathrm{SZA}, \lambda)$

Here it must be noted that using the transmittances in Eq. (2), the horizontal global transmittance $\left(T_{\mathrm{GHI}}\right)$ is given by the sum of the normal direct transmittance $\left(T_{\mathrm{DNI}}\right)$ and the diffuse horizontal transmittance ( $\left.t_{\mathrm{DIF}}\right)$. As can be seen, the explicit dependence on the $\cos (\mathrm{SZA})$ of Eq. (1) is removed in Eq. (2). The advantage of using transmittance functions instead of irradiance values is because in this way it works with normalized functions whose values are always equal to or less than 1. As well as this, Eq. (2) is also valid for integrated values of solar radiation, which translates to 
the definitions of the clearness indices $K_{n}$ and $K_{T}$ for normal direct and global solar components, respectively, where $K_{n}=T_{\mathrm{DNI}}$ and $K_{T}=T_{\mathrm{GHI}}$, in this case referring to instantaneous and integrated values. Therefore, Eq. (2) is now written as $K_{n}=K_{T}(1-K)$, where $K$ is the fraction of the diffuse radiation ( $K=\mathrm{DIF} / \mathrm{GHI})$. These indices are widely used by the solar energy community and are the base of the so-called separation solar radiation models under all sky conditions (Gueymard and Ruiz-Arias, 2016; Yang and Boland, 2019).

The direct normal spectral solar component at any level of the atmosphere (expressed as radiance or irradiance quantities) is currently given by the Beer-Lambert-Bouguer (BLB) law. This law is a solution of the radiative transfer equation (RTE) when applied only to direct component. The simplicity of the resulting solution makes it possible to consider scattering by molecules and particles, and absorption by atmospheric gases as independent processes (non-interaction between them). This allows us to present $T_{\mathrm{DNI}}$ as a product of independent transmittances of the different atmospheric constituents: ozone, water vapour, aerosols, molecules, etc. (see Sect. 3.1).

Therefore, it is standard in radiative transfer theory to separate the modelling of solar radiation into its two components, direct normal and diffuse, and solving the RTE for each component, considering a dispersive or scattering medium without absorption of atmospheric gases. However, solving the RTE for the diffuse component is not a straightforward task and different analytical and numerical methods have been developed depending on the approaches or the specific problem involved (see classical books on radiative transfer theory: Chandrasekhar, 1960; Sobolev, 1963; Kondratyev, 1969; Lenoble, 1985, 1993; Liou, 1992, 2002; Zdunkowski et al., 2007; Kokhanovsky, 2008; see also the different solvers used in libRadtran).

Since we are interested in solar spectral irradiances or fluxes and not radiances a more convenient approach for solving the RTE is addressed by those methods known as "two streams" or "two flux" which indistinctly solve the RTE for the diffuse component only or for the global component. The "two flux" methodology was extensively developed in the 70-80 s and presents numerous variants (Joseph et al., 1976; Meador and Weaver, 1980; Zdunkowski et al., 1980; King and Harshvardhan, 1986; Liou, 1992; Fouquart and Bonnel, 1980; Durán, 1997; Räisänen, 2002; Lin et al., 2019).

Although less frequent, another possible option is to consider other methods, such as the original method of "addition of layers" in a one-dimensional scattering medium, developed by Ambartsumian (Sobolev, 1963; Nikoghossian, 2009), which does not consider the RTE. The analytical expression obtained for the transmittance of the global solar irradiance in a scattering medium (without atmospheric gas absorption) composed of aerosols or molecules (or a mixture of both components) is the core of the SSolar-GOA model (see Sect. 3.2). After that, this transmittance is multiplied by the absorption transmittance of atmospheric gases giving the above spectral $T_{\mathrm{GHI}}$ of Eq. (2) assuming non-interaction between scattering and gas absorption.

\subsection{The libRadtran package}

The libRadtran package is a software library for radiative transfer calculations of solar and thermal radiation (from $120 \mathrm{~nm}$ to $100 \mu \mathrm{m}$ ) in the Earth's atmosphere. The central part of the software package is an executable program called uvspec which was initially developed for UV radiation evaluation and which has undergone numerous extension and improvements to reach the current libRadtran estructure (Mayer and Kylling, 2005; Emde et al., 2016). It is freely available at the web page http://www.libradtran.org (last access: 23 May 2021), which contains all the available information about the program including the user's guides (libRadtran user's guide, $2015,2020)$ and the software source code. The libRadtran package contains a complete treatment of the inputs, utilities, methods, and outputs to handle the complex structure that radiative transfer models have, allowing for the determination of the field radiation (radiances, irradiances, polarization, etc.) in the atmosphere. Therefore, libRadtran is a set of RT codes which serves as a reference tool which is widely used by the scientific community in different fields of study.

libRadtran requires detailed information specified in input files provided by the same package or constructed by the users, for example the Mie program (see libRadtran user's guide chap. 4) for the calculation of aerosol optical properties. For the irradiance values, the direct normal component is calculated based on the BLB in a similar way to SSolarGOA (described in next Sect. 3.1). For our simulations, the algorithm for the spectral solar diffuse horizontal irradiance used the sdisort RTE solver with 10 streams. The global spectral radiation is constructed by the sum of direct horizontal plus diffuse horizontal components. All the atmospheric gases were considered in libRadtran for the simulations. To compare with the SSolar-GOA model, the adequate options of libRadtran are the "spectrally resolved calculation" for the UV and visible spectral range and the "pseudo-spectral" in the infrared solar region (i.e. water vapour, oxygen and carbon dioxide), represented by the band parameterization of the LOWTRAN7 code taken by the SBDART model and adopted in libRadtran (Kneizys, 1988; Mayer and Kylling, 2005). Therefore, the latter option was taken by us in accordance with the building of the SSolar-GOA model.

A midlatitude summer atmospheric profile with a default of an aerosol profile in the summer season was chosen, but the contribution of aerosols was constructed on the alpha and beta Angström turbidity parameters (they are also represented in the text by the symbols $\alpha$ and $\beta$, respectively; see next sections). It must be noted that under clear skies the aerosol contribution is the most important factor for solar irradiance, and the spectral behaviour of $\operatorname{AOD}(\lambda)$ is given by the alpha parameter. The spectral $\operatorname{AOD}(\lambda)$ is the most 
relevant input for a proper comparison between libRadtran and our model since it determines the curvature shape and height of the transmittance of the direct normal component. The other two aerosol parameters, the asymmetry parameter $(g)$ and single scattering albedo (SSA), are of secondary importance and are taken as fixed values (not wavelength dependent) in libRadtran and SSolar-GOA models.

\section{Description of the SSolar-GOA radiative transfer model}

The SSolar-GOA model is designed based on our previous experience gained through using simple empirical parametric spectral solar radiation models (Cachorro et al., 1985) and more complex radiative transfer codes (Cachorro et al., 1997) in an attempt to cover the gap between these two extreme configurations. This is a physical, fast, efficient, and accurate spectral radiative transfer model to estimate the spectral components of solar radiation at surface level or at a given altitude considered as the bottom surface in the model, and it covers the solar spectral range from 300 to $2600 \mathrm{~nm}$. The crux of the model is the simple analytical parameterized expression for the spectral scattering transmittance function of the mixed layer of molecules and aerosols. This expression was developed by Ambartsumian (Sobolev, 1963; Nikoghossian, 2009) for a one-dimensional scattering medium. The atmosphere is assumed to be a single homogeneous plane parallel layer. Absorption by atmospheric gases is given by the parameterized transmittances based on "band model approach" (Pierluissi and Maragoudakis, 1986; Pierluissi and Tsai, 1987; Pierluissi et al., 1989) which were applied to the LOWTRAN7 code (Kneizys, 1988).

The model presents a moderate spectral resolution, aimed at operation of $1-10 \mathrm{~nm}$, depending on the selected spectral resolution of the extraterrestrial solar spectra in combination with that of the absorption coefficients of the absorbing gases. The accuracy of the model is in consonance with the error associated with experimental data of the most common commercial spectroradiometers, about $2 \%-5 \%$. Below, we present a detailed description of the SSolar-GOA model, first to evaluate the direct normal component and then the global spectral irradiance, both as independent components. The diffuse spectral irradiance is derived from the other two quantities. The model may be easily adapted to the case of limited available information about the model's input parameters. The SSolar-GOA v1.0 is released as free and opensource software. It is implemented in Python offering portability across architectures and operating systems. For download instructions, see the Code and data availability section.

\subsection{The spectral direct normal solar irradiance}

Assuming the validity of the BLB law, the spectral irradiance of the direct normal component of solar radiation, DNI (SZA, $z$ ), at any time (given by the SZA) and at any vertical altitude $z$ of the atmosphere, is given by

$$
\begin{aligned}
\mathrm{DNI}(\mathrm{SZA}, z, \lambda) & =D F_{o}(\lambda) T_{\mathrm{DNI}}(\mathrm{SZA}, z, \lambda) \\
& =D F_{o} \exp (-\tau(z, \lambda) m),
\end{aligned}
$$

where $\tau(z, \lambda)$ is the spectral atmospheric optical thickness at the level $z$, or the altitude in the atmosphere which accounts for scattering by molecules and particles as well as absorption by atmospheric gases. $F_{o}(\lambda)$ is the spectral irradiance at the top of atmosphere (extraterrestrial spectrum) and $D$ is the correction factor of the Earth-Sun distance.

Considering the ground surface level $z=0, \tau(z=0, \lambda)=$ $\tau(\lambda)$ represents the total spectral optical thickness of the atmosphere at the site. $m$ is the relative optical air mass giving the slant path of the Sun's rays relative to the zenith, which is given by $m=1 / \cos$ (SZA) for a plane-parallel atmosphere. For a spherical atmosphere, more accurate expressions for $m$ are necessary when the SZA is greater than $70^{\circ}$; in order to account for the curvature of the atmosphere and the refraction effects, various expressions were developed for each atmospheric component (Kasten and Young, 1989; Gueymard, 1995, 2005; Tomasi et al., 1998; Chiron de la Casinière and Cachorro Revilla, 2008; Rapp-Arrarás and Domingo-Santos, 2008).

As mentioned, the advantage of solving the RTE only for the direct normal component is that $T_{\mathrm{DNI}}$ can be calculated as a product of transmittances due to the different processes of attenuation due to the different atmospheric components, where the non-interaction between these processes is implicitly assumed.

$T_{\mathrm{DNI}}(\mathrm{SZA}, \lambda)=T_{\mathrm{R}}(\mathrm{SZA}, \lambda) T_{\mathrm{a}}(\mathrm{SZA}, \lambda) T_{\mathrm{gas}, i}(\mathrm{SZA}, \lambda)$

In Eq. (4), the different transmittances are given by exponential functions of the optical thickness of each process: the scattering by molecules or Rayleigh scattering, $\tau_{R}(\lambda)$; scattering by aerosols, $\tau_{\mathrm{a}}(\lambda)$ or $\operatorname{AOD}(\lambda)$; and the absorption by atmospheric gases, $\tau_{\mathrm{gas}, i}(\lambda)$ (subscript $i$ refers to different selected gases), multiplied by the corresponding relative air mass.

$$
\begin{array}{r}
T_{\mathrm{DNI}}(\mathrm{SZA}, \lambda)=\exp (-\tau(\lambda) m)=\exp \left(-\tau_{\mathrm{R}}(\lambda) m_{\mathrm{R}}\right) \\
\exp \left(-\tau_{\mathrm{a}}(\lambda) m_{\mathrm{a}}\right) \exp \left(-\tau_{\mathrm{gas}, i}(\lambda) m_{\mathrm{gas}, i}\right)
\end{array}
$$

The BLB law of Eq. (3) is also valid for integrated irradiance values (i.e. removing the wavelength dependency), where $\tau$ represents the integrated total optical thickness of the atmosphere, but Eqs. (4)-(5) are only valid for spectral values (Cachorro et al., 2000b, a; Utrillas et al., 2000). Despite this, Eq. (4) is taken as a good approach for the "broadband solar models" (Gueymard, 2008; Ruiz-Arias and Gueymard, 
2018) assuming that the transmittance of each atmospheric component is an integrated value over the entire solar range. According to Eq. (5), it follows that

$$
\tau(\lambda) m=\tau_{\mathrm{R}}(\lambda) m_{\mathrm{R}}+\tau_{\mathrm{a}}(\lambda) m_{\mathrm{a}}+\tau_{\mathrm{gas}, i}(\lambda) m_{\mathrm{gas}, i} .
$$

Therefore, the total optical thickness of the atmosphere is given by the sum of the different optical thicknesses due to the different attenuation processes of solar radiation assuming the same relative optical air mass. According to Eqs. (5) and (6) we can use either transmittances or optical thickness. Observe that optical thickness is a dimensionless parameter like the relative optical air mass. Although it is usual to consider $m=m_{\mathrm{R}}=m_{\mathrm{a}}$, for atmospheric gases it is more convenient to use different expressions specifically determined for each absorbing gas (Gueymard, 1995; Tomasi et al., 1998).

There are different parameterized expressions to evaluate the Rayleigh optical thickness (Teillet, 1990; Gueymard, 1995; Bodhaine et al., 1999; Tomasi et al., 2005) with insignificant differences for our purpose, and hence the Gueymard (1995) formula was taken for the SSolar-GOA model.

$$
\tau_{\mathrm{R}}(\lambda)=\frac{1}{117.2594 \lambda^{4}-1.3215 \lambda^{2}+0.00032-0.000076 \lambda^{-2}}
$$

Since this expression is evaluated at sea level, it is necessary to multiply by the factors $P$ and $P_{o}$, where $P$ and $P_{o}$ are the pressure at the site (or altitude) and the sea-level pressure, respectively. The transmittance of scattering by aerosols $T_{\mathrm{a}}$ (SZA) is accounted for by a simple approach for the aerosol optical depth given by the Angström formula (Ångström, $1929,1930,1961,1964)$. This is an empirical expression extensively used in the field of aerosol studies and in solar radiation applications (Cachorro et al., 1987b, c, 2000a, b) and is expressed as follows:

$$
\tau_{\mathrm{a}}(\lambda)=\beta \lambda^{-\alpha},
$$

where $\alpha$ (alpha) and $\beta$ (beta) are the Ångström turbidity parameters. The $\alpha$ parameter, also called Ångström exponent (the symbol AE is now more commonly used in place of $\alpha$ ), is related to the bulk size of the particles, and the $\beta$ parameter is the aerosol optical thickness at $1 \mu \mathrm{m}$ wavelength. Bear in mind that this is an empirical expression which may be applied to a given extended spectral range. Frequently, two wavelengths can be selected and hence Eq. (9) allows for the determination of the $\alpha$ parameter:

$$
\frac{\tau_{\mathrm{a}}\left(\lambda_{1}\right)}{\tau_{\mathrm{a}}\left(\lambda_{2}\right)}=\left(\frac{\lambda_{1}}{\lambda_{2}}\right)^{-\alpha} \text {. }
$$

When several wavelengths are available, such as in Sun photometers or spectroradiometers, the $\alpha-\beta$ parameters can be determined simultaneously by a linear regression of $\log \left[\tau_{\mathrm{a}}(\lambda)\right]$ versus $\log [\lambda]$ (Cachorro et al., 1987b, c, 1989, 2000b; Martìnez-Lozano et al., 1998). In this case, different values of the $\alpha-\beta$ pair are obtained depending on the selected spectral range (or wavelengths). Therefore, some solar radiation models use more than one pair of $\alpha-\beta$ values to cover the entire solar spectral range (Gueymard and Myers, 2008). However, in the SSolar model, only a pair of values is taken. Despite its simplicity, the Angström formula has proven to be an excellent approach for modelling the spectral behaviour of the aerosol optical depth, $\operatorname{AOD}(\lambda)$. In RT studies, the aerosol optical thickness and other optical properties are determined by the Mie scattering theory (Bohren and Huffman, 1998; Cachorro and Salcedo, 1991). In Cachorro et al. (2000a), experimental direct normal irradiance measurements of the LI1800 together with rigorous Mie scattering expressions were used to determine the distribution of aerosol particle size and other aerosol parameters.

The absorption processes by atmospheric gases must be accounted for and are given by different transmittances. In the solar spectral range, the SSolar-GOA model uses tabulated absorption coefficients of water vapour $\left(\mathrm{H}_{2} \mathrm{O}(\mathrm{v})\right)$, ozone $\left(\mathrm{O}_{3}\right)$, oxygen $\left(\mathrm{O}_{2}\right)$, nitrogen dioxide $\left(\mathrm{NO}_{2}\right)$, and carbon dioxide $\left(\mathrm{CO}_{2}\right)$, but the current version only considers water vapour, ozone, and oxygen because of the low absorption features of the other two components and the necessity of a rapid running of the model. These absorbing gases are represented by the product of the different transmittances.

$$
\begin{gathered}
T_{\mathrm{gas}, i}(\mathrm{SZA}, \lambda)=T_{\mathrm{H}_{2} \mathrm{O}}(\mathrm{SZA}, \lambda) T_{\mathrm{O}_{3}}(\mathrm{SZA}, \lambda) \\
T_{\mathrm{O}_{2}}(\mathrm{SZA}, \lambda)
\end{gathered}
$$

The selective line absorption of these molecular gases is treated under the "band model approach" method mentioned above. This results in parameterized expressions which are adequate for models of low-median spectral resolution, as explained below. The transmittance of ozone absorption is given by the following expression:

$T_{\mathrm{O}_{3}}=\exp \left(-\tau_{\mathrm{O}_{3}}(\lambda) m_{\mathrm{O}_{3}}\right)=\exp \left(-C_{\mathrm{O}_{3}}(\lambda) L_{\mathrm{O}_{3}} m_{\mathrm{O}_{3}}\right)$,

where $\tau_{\mathrm{O}_{3}}(\lambda)$ is the spectral ozone optical thickness. $C_{\mathrm{O}_{3}}(\lambda)$ refers to the ozone absorption coefficients (or cross section, depending on the units taken), which carry the wavelength dependence, and $L_{\mathrm{O}_{3}}$ is the columnar ozone content. Usually, $L_{\mathrm{O}_{3}}$ is given in Dobson units, $\mathrm{DU}\left(1 \mathrm{DU}=1 \mathrm{~cm}\right.$-atm $\left.\times 10^{-3}\right)$, and thus the absorption coefficients are given in $(\mathrm{cm}-\mathrm{atm})^{-1}$. The relative optical air mass, $m_{\mathrm{O}_{3}}$, is given by the expression from Komhyr (1980). Ozone in the region of $280-350 \mathrm{~nm}$ corresponds to the Hartley (200-310 nm) and Huggins (300$350 \mathrm{~nm}$ ) bands, and the Chappuis band in the visible range $(400-650 \mathrm{~nm})$. The cross sections taken in our model for the UV region are those from Bass and Paur (1985). The original values are given with a spectral resolution of $0.05 \mathrm{~nm}$, so they were convoluted with a triangular slit function of $7 \mathrm{~nm}$ of FWHM and evaluated or interpolated in $1 \mathrm{~nm}$ steps. The cross sections were also provided for three different temperatures, and $226 \mathrm{~K}$ was selected for our model. For the visible Chappuis band, the $C_{\mathrm{O}_{3}}$ values were taken from Amoruso et al. (1990), Anderson and Mauersberger (1992), and Brion 
et al. (1998). These values were also changed to the spectral resolution as before. These $C_{\mathrm{O}_{3}}(\lambda)$ values are sufficient to predict solar irradiance values (Redondas et al., 2014; Orphal et al., 2016).

The transmittance of water vapour is given by the parameterized expression of Pierluissi et al. (1989):

$$
\begin{aligned}
T_{\mathrm{H}_{2} \mathrm{O}}(\lambda) & =\exp \left(-\tau_{\mathrm{H}_{2} \mathrm{O}}(\lambda) m_{\mathrm{H}_{2} \mathrm{O}}\right) \\
& =\exp \left[\left(-C_{\mathrm{H}_{2} \mathrm{O}}(\lambda) W m_{\mathrm{H}_{2} \mathrm{O}}\right)^{a}\right],
\end{aligned}
$$

where $C_{\mathrm{H}_{2} \mathrm{O}}(\lambda)$ refers to the absorption coefficient of water vapour which was taken from LOWTRAN7 with a spectral resolution of $20 \mathrm{~cm}^{-1}$ in steps of $5 \mathrm{~cm}^{-1}$. These coefficients were accommodated as before at a spectral resolution of $7 \mathrm{~nm}$ and step of $1 \mathrm{~nm}$. The parameter " $a$ " presents a smooth dependence on wavelength and is given by Pierluissi et al. (1989) for each water absorption band. $W$ is the equivalent absorber amount over the vertical which is related to the amount of absorber, $U$, or precipitable water vapour, $\mathrm{PWV}$, expressed in $\mathrm{cm}$ or $\mathrm{g} \mathrm{cm}^{-2}$ by

$W=\left(\frac{P_{\mathrm{e}}}{P_{\mathrm{o}}}\right)^{n}\left(\frac{T_{\mathrm{o}}}{T_{\mathrm{e}}}\right)^{m} U$.

The above expression applied the Curtis-Godson approximation to the whole single layer of the atmosphere for our model, where $P_{\mathrm{e}}$ and $T_{\mathrm{e}}$ are the effective pressure and temperature of the atmosphere, respectively (we take those of the standard atmosphere), and $T_{o}$ and $P_{o}$ are the values at standard conditions. The parameters $n$ and $m$ are also given by Pierluissi et al. (1989) for each band of water vapour. An integration is used to model several atmospheric layers, where $P_{\mathrm{e}}$ and $T_{\mathrm{e}}$ are substituted for the values $P(z)$ and $T(z)$, and $U$ by $\mathrm{d} U=\rho_{\mathrm{v}}(z) \mathrm{d} z$, where $\rho_{\mathrm{v}}(z)$ is the profile of water vapour density.

The transmittance of oxygen is treated with an expression similar to that of water vapour (Pierluissi and Maragoudakis, 1986). In contrast to the variability of water vapour, oxygen is constant in the atmosphere. The value used in our model for the equivalent vertical oxygen content was $87068.53 \mathrm{~cm}$-atm, corresponding to the midlatitude summer atmosphere. This value does not differ substantially for other atmospheres, and therefore, no variation in transmittance was observed. In all the absorbing gas transmittances, the amount of absorbing gas is given in units of $\mathrm{cm}$-atm or in $\mathrm{g} \mathrm{cm}^{-2}$ and hence the absorption coefficients have the inverse units. As can be seen, the procedure followed for the absorption gas transmittances in our model is equivalent to the "pseudo-spectral calculations" according to libRadtran.

\subsection{The total (global) scattering transmittance for a mixed aerosol-molecule atmosphere}

The simplicity of the SSolar_GOA model is based on the parameterized Eq. (14) to calculate the total scattering transmittance $T_{\text {Mix }}(\mathrm{SZA})$ for a mixed layer of aerosols and molecules, considering the interaction between the two scattering processes. These Eqs. (14)-(16) are obtained by the original method of "addition of layers" in a onedimensional medium developed by Ambartsumian (Sobolev, 1963; Nikoghossian, 2009). For simplicity, the wavelength is removed in some of the next Eqs. (14)-(16), but the generic parameters $\tau(\lambda), \omega(\lambda)$, and $g(\lambda)$ carry this wavelength dependence, and the following subscripts are $R$ for the molecules, a for the aerosols, and Mix for the mixture. Equations (14)-(16) are as follows:

$T_{\text {Mix }}(\mathrm{SZA})=\frac{\left(1-r_{o}^{2}\right) \exp \left(-k \tau_{t} m\right)}{1-r_{o}^{2} \exp \left(-2 k \tau_{\mathrm{t}} m\right)}$,

where $\tau_{\mathrm{t}}(\lambda)$ is the total scattering optical depth $\left(\tau_{\mathrm{t}}=\tau_{\mathrm{a}}+\tau_{\mathrm{R}}\right)$, and $m$ is the relative optical air mass. The parameters $r_{o}$ and $k$ are given by

$r_{o}=\frac{k-1+\omega_{\text {Mix }}}{k+1-\omega_{\text {Mix }}} \quad k=\left(1-\omega_{\text {Mix }}\right)\left(1-\omega_{\text {Mix }} g_{\text {Mix }}\right)$,

where $\omega_{\text {Mix }}$ and $g_{\text {Mix }}$ are the single scattering albedo and the asymmetry parameter of the mixed layer of aerosols and molecules defined by the corresponding parameters of individual molecules ( $R$ ) and aerosols (a). They are given by the following expressions:

$\omega_{\text {Mix }}=\frac{\tau_{\mathrm{R}}+\omega_{\mathrm{a}} \tau_{\mathrm{a}}}{\tau_{\mathrm{t}}}$, with $\quad \omega_{\mathrm{a}} \neq 1, \quad g_{\mathrm{Mix}}=\frac{g_{\mathrm{a}} \tau_{\mathrm{a}}}{\tau_{\mathrm{t}}}$.

However, we must state that the transmittance of Eq. (14) may be also used to evaluate an isolated aerosol layer, represented by the scattering aerosol transmittance, $T_{\mathrm{a}}$. In this case, we need an expression for the scattering transmittance for an isolated pure Rayleigh atmosphere, $T_{\mathrm{R}}$, for example that given in Vermote and Tanré (1992). The total transmittance of the scattering atmosphere of the aerosol and molecular mixed layer is obtained as the product $T_{\mathrm{a}-\mathrm{R}}=T_{\mathrm{a}} T_{\mathrm{R}}$, where it is implicitly assumed that there is no interaction between the molecules and aerosols. Therefore, $T_{\mathrm{a}-\mathrm{R}}$ is equivalent to $T_{\mathrm{Mix}}$, but not the same. No significant differences have been found between these two approaches for moderate atmospheric aerosol loads. Scattering and gas absorption are applied to a single atmospheric homogeneous layer in the SSolar-GOA under the consideration of non-interaction of both processes, which simplify considerably the formulation of the model.

The above expressions were derived assuming a zero reflectance or albedo of the underlying surface (considered as a black body), so its influence must be taken into account by the contribution of the multiple reflections between it and the atmosphere. For this effect, we have followed the formulation of Lenoble (1998), where an amplification factor independent of the SZA is defined as

f_amp $(\lambda)=1 /(1-\rho S(\lambda))$, 
where $\rho$ is the surface albedo taken in the model as a constant value and considered Lambertian. $S(\lambda)$ is the spectral atmospheric albedo of the mixed Rayleigh-aerosol layer, given by the sum of both scattering components (Tanré et al., 1986; Vermote and Tanré, 1992).

$$
\begin{aligned}
& S(\lambda)=S_{\mathrm{R}}(\lambda)+S_{\mathrm{a}}(\lambda) \\
& S_{\mathrm{R}}(\lambda)=\frac{\tau_{\mathrm{R}}}{2+\tau_{\mathrm{R}}}\left(1-\exp \left(-2 \tau_{\mathrm{R}}\right)\right) \\
& S_{\mathrm{a}}(\lambda)=\frac{g^{\prime} \tau_{\mathrm{a}}}{2+g^{\prime} \tau_{\mathrm{a}}}\left(1-\exp \left(-g^{\prime} \tau_{\mathrm{a}}\right)\right) \\
& \text { with } g^{\prime}=\omega_{\mathrm{a}}\left(1-g_{\mathrm{a}}\right)
\end{aligned}
$$

As previously mentioned, all Eqs. (14)-(20) are wavelength dependent by means of the corresponding parameters. However, due to the difficulty of providing accurate spectral values for the aerosol single scattering albedo $\omega_{\mathrm{a}}$ (or SSA) and the asymmetry parameter $g_{\mathrm{a}}$, these two parameters are taken as constant values in the SSolar-GOA model. These values for the different types of aerosols are given in different publications (Dubovik et al., 2002; Hamill et al., 2016). Finally, we call attention to the total number of expressions/formulas which define the SSolar-GOA model in comparison with other spectral models of similar characteristics given in the bibliography (e.g. Bird, 1984; Gueymard, 1995, 2005; Xie and Sengupta, 2018), which results in a major complexity and computational cost.

\subsection{The model input parameters}

According to the above expressions, the input parameters for the SSolar-GOA model are as follows:

- the solar zenith angle, SZA (degrees);

- the Julian day, $N$;

- the pressure at the site, $P$ (in mbar);

- the surface albedo, $\rho$.

The aerosol dimensionless parameters are as follows:

- alpha and beta $(\alpha, \beta)$, Ångström turbidity coefficients

- the aerosol single scattering albedo, $\omega_{\mathrm{a}}$ (commonly named SSA);

- the aerosol parameter of asymmetry, $g_{\mathrm{a}}$, and for the absorption of atmospheric gases

the total column ozone content $L_{\mathrm{O}_{3}}$ (in Dobson units, DU) and the content of precipitable water vapour $U$ (in $\mathrm{cm}$ or $\mathrm{cm}-\mathrm{pr}$ ).

Hence, a total of 10 input parameters are required. $N$ is the Julian day (from 1 to 365) which is required as an input to correct the Earth-Sun distance, $D$, which multiplies the extraterrestrial irradiance spectrum. The pressure, $P$, at

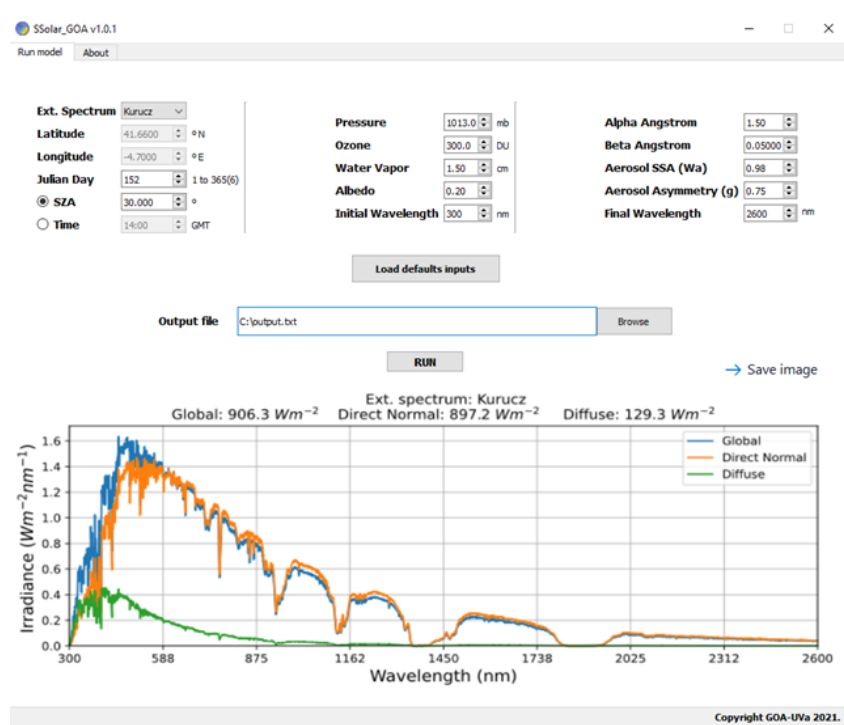

Figure 1. Screenshot of SSolar-GOA v1.0.1 with default inputs configured.

the site (altitude of the bottom surface) is required to account for the correction of altitude in the Rayleigh scattering optical thickness. The $\alpha$ and $\beta$ Ångström coefficients build the aerosol optical thickness, AOD $(\lambda)$, for the whole solar spectral range. Observe that another possible option for the spectral construction of the modelled AOD is to take 4-6 values of the spectral AOD provided by AERONET. As mentioned, the single scattering albedo $\omega_{\mathrm{a}}$ (or SSA) and the asymmetry parameter $\mathrm{g}_{\mathrm{a}}$ are taken as constant values because these two parameters are of the second order of importance in relation to the contribution of the aerosol optical depth. As well as this, the Julian day is also required if GMT (Greenwich Mean time, a.k.a. UTC) is used as input instead of the SZA, but in this case it is also necessary to add the latitude and longitude of the site in order to calculate the SZA, and hence a total of 12 parameters must be entered into the model. GMT (or also local time) is currently used when building a set of spectra or when daily solar irradiance values are calculated, since the SSolar-GOA model may also calculate instantaneous integrated irradiance values.

Under clear-sky conditions, AOD and water vapour content are the two atmospheric parameters of major importance for irradiance values, and ozone and oxygen absorption are also considered because of their strong spectral absorbing features. Other minor absorbing gases, such as $\mathrm{CO}_{2}$ and $\mathrm{NO}_{2}$, are included in the file of absorbing coefficients but are neglected in the running of the current version of the SSolar-GOA model, partially due to their low contribution, but mainly for simplicity and calculation speed.

Generally, the spectral resolution of the model is given by the spectral resolution taken for the spectrum of the extraterrestrial solar irradiance according to that of the absorption coefficients of atmospheric gases. In our model, we 
can select three different extraterrestrial work files, given by Wehrli (1985), Kurucz (1992), and Gueymard (2004), as they appear in Fig. 1 together with the default input parameters above described.

\section{Results: performances/validation}

\subsection{Comparison between SSolar-GOA model and libRadtran}

The comparison between the SSolar-GOA model and libRadtran is carried out as a theoretical exercise, given the latter as a framework reference. For the comparison with experimental spectral irradiance data, the SSolar-GOA model is fed with measured values of the required atmospheric input parameters. Figure 2 shows a set of simulated solar irradiance spectra at sea level by the SSolar-GOA model at three SZAs: 6,30 , and $60^{\circ}$, with typical values of the input parameters (given at the top of the figure) under clear-sky conditions. This figure illustrates the main characteristics of solar radiation components: horizontal irradiances of direct, diffuse, and global components and the direct normal irradiance. Irradiance values of direct-normal and global solar components show the well-known spectral distribution of solar radiation and their behaviour on the wavelength due to the absorption by atmospheric gases. They increase quickly from near zero at $300 \mathrm{~nm}$ to the maximum at visible wavelengths around $500 \mathrm{~nm}$ (reaching $\sim 1800, \sim 1600$, and $\sim 800 \mathrm{~W} \mathrm{~m}^{-2} \mathrm{~nm}^{-1}$ at $\mathrm{SZA}=6,30$, and $60^{\circ}$, respectively, for the global irradiance) and decreasing very slowly along the wavelengths of infrared range. Moreover, the features of water vapour and oxygen band absorptions are the most evident. Overall, the prevalence of global irradiance can be highlighted for low SZA values, but the inverse situation happens when the SZA increases. In this case, direct normal irradiance prevails, starting in the infrared wavelength region and then spreading throughout the whole spectral range, with a greater separation of the spectra of both components.

As typical characteristics, the direct normal irradiance shows a less pointed shape than the global component and a smoother curvature at peak values (from 470 to $700 \mathrm{~nm}$ ) for increasing SZAs and also the strong variation of these solar irradiances with the SZA in the first part of the spectrum (440 to $1100 \mathrm{~nm}$ ) in relation to this last part of the spectrum $(1000-2500 \mathrm{~nm})$. On the other hand, the low values of the diffuse irradiance in relation to the other components under clear skies present the particularity of their minor variations with the SZA and their maximum at the UV region. Thinking about solar radiation as an energy source, it must be noted that irradiance values for $\mathrm{SZA}=6^{\circ}$ are only frequent in sites near the tropics where these low SZAs are reached, while SZAs from 30 to $60^{\circ}$ are most frequent in midlatitudes and high latitudes where the influence of $\cos$ (SZA) on direct
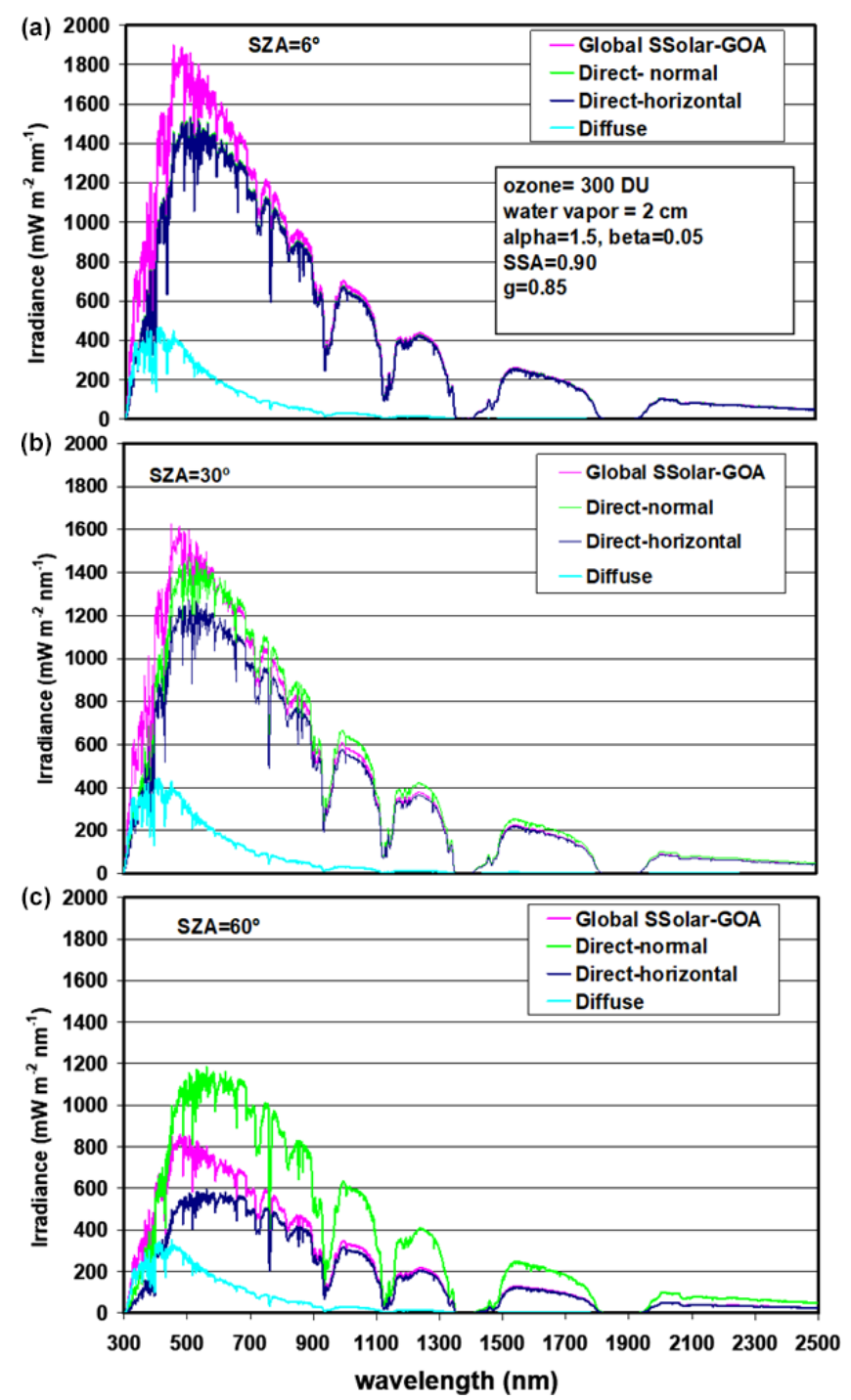

Figure 2. Global, direct normal, direct-horizontal, and diffuse spectral solar irradiances simulated at sea surface level according to the input parameters shown in the figure for SZAs of 6,30 , and $60^{\circ}$, respectively (from top to bottom).

horizontal irradiance values are very important and hence greatly influence the global component.

Figure 3 shows the comparison between both models for the direct normal irradiance at $\mathrm{SZA}=6,30$, and $60^{\circ}$ from top to bottom, respectively, with typical values of the input parameters (shown at the top of the figure) corresponding to middle-latitude sites. For better visualization, we have selected the $300-1100 \mathrm{~nm}$ spectral range. As can be seen, the results of both models are nearly identical, with relative differences ((libRadtran - SSolar-GOA) / libRadtran) around $0.5 \%$ or less than $1 \%$ in the non-band absorption regions throughout the entire solar spectral range and covering this large range of SZAs. However, high relative differences with strong and rapid variations, going from positive 

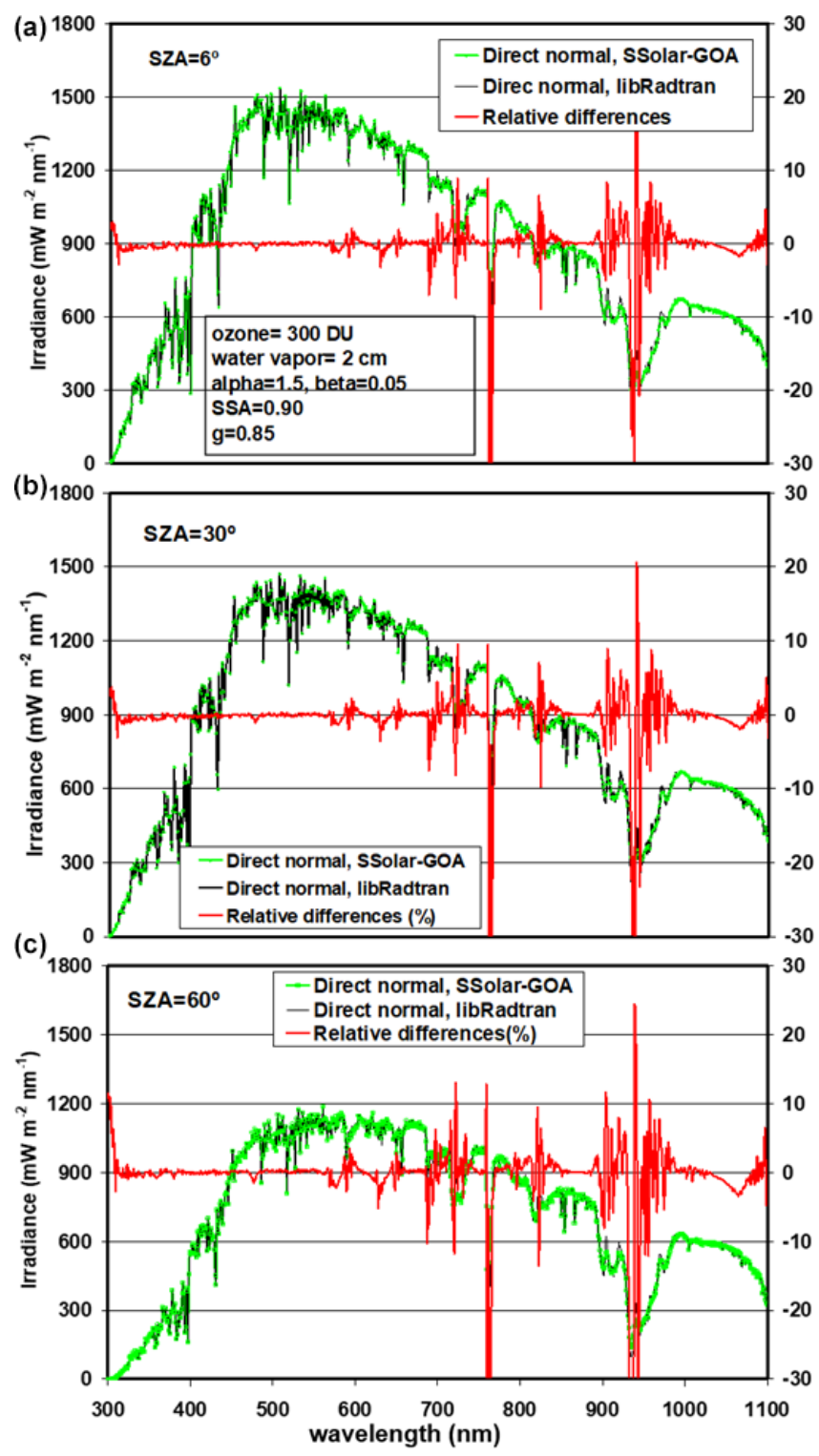

Figure 3. Comparison between libRadtran and SSolar-GOA models for direct normal irradiance at $\mathrm{SZA}=6,30$, and $60^{\circ}$ respectively (from top to bottom), with input parameters shown at the top of the figure. Right $y$ axis indicates the relative differences in percentage in all figures ((libRadtran - SSolar-GOA) / libRadtran).

to negative values (about $\pm 30 \%$ ), are shown in the regions of the absorption bands of water vapour and oxygen (mainly at $940 \mathrm{~nm}$ for water vapour and the oxygen A band (759$771 \mathrm{~nm})$ ). This behaviour must be due to the different spectral resolution in this regions of strong absorption, where the cause could be the slightly different values of the absorption coefficients of each model. Minor differences are found in the visible region due to the smooth and low absorption of the ozone absorption band $(400-650 \mathrm{~nm})$ and due to the very low absorption of the water vapour bands.
As already indicated, although both models employed the LOWTRAN7 band model parameterization and similar original coefficients for absorption in the infrared, it seems that the absorption coefficients have undergone a slightly different mathematical handling related to the convolution and interpolation processes. The original LOWTRAN7 absorption coefficients are given in wavenumber (in $\mathrm{cm}^{-1}$ ) and not in wavelength (in $\mathrm{nm}$ ). Therefore, the transformation from " $\mathrm{cm}^{-1}$ " to "nm" gives rise to an inhomogeneous spectral interval of the model, requiring a subsequent interpolation and smoothing (or convolution with a given FWHM) to have a constant step interval, which also depends on the spectral resolution chosen for the model. For example, at the wavelength $\lambda=1 \mu \mathrm{m}(1000 \mathrm{~nm})$, a spectral resolution of $20 \mathrm{~cm}^{-1}$ corresponds to $2 \mathrm{~nm}$, but at $\lambda=0.5 \mu \mathrm{m}(500 \mathrm{~nm})$ the spectral resolution is $0.5 \mathrm{~nm}$. Observing the irradiance values of the spectra and the shape features of these two absorption bands for both models, it is evident that libRadtran presents a slightly higher spectral resolution than the SSolar-GOA model in the regions of gas absorption. For both models, the extraterrestrial spectrum (Kurucz, 1992) is taken with a spectral resolution of $1 \mathrm{~nm}$. Therefore, in the intervals of non-absorption both models present the same spectral resolution and hence they show an exact coincidence for each $\mathrm{nm}$, since the transmittance of scattering processes have a smooth behaviour, and hence the spectral resolution is given by the extraterrestrial spectrum.

For a better visualization of these differences and to confirm the above reasoning, Fig. 4 shows in detail the comparison of both models in the region of the $940 \mathrm{~nm}$ water vapour absorption band for direct normal (a) and global irradiances (b) at $\mathrm{SZA}=30^{\circ}$. A perfect spectral correspondence (point to point) can be seen in the region of $840-890 \mathrm{~nm}$ (just before the " $940 \mathrm{~nm}$ absorption band" begins) due to the absorption coefficients being zero. On the other hand, one can observe the lower spectral resolution of the SSolar model with a slight smoother behaviour than libRadtran into the " $940 \mathrm{~nm}$ absorption band". This is because the absorption coefficients of the SSolar-GOA model were convoluted with a slit function of FWHM equal to $7 \mathrm{~nm}$.

Although the relative differences in the regions of high absorption by water vapour and oxygen may seem very high, this is the typical behaviour when the spectral resolution of two models is not the same. This is also evident when observing the sharp shape of the A band of oxygen in the libRadtran package with respect to the SSolar-GOA model. Other minor differences between both models are due to the fact that by default the libRadtran considers the complete list of absorption atmospheric gases (such as $\mathrm{NO}_{2}, \mathrm{CO}_{2}$, minor gases, etc.) and SSolar-GOA only considers ozone, water vapour, and oxygen.

Figure 5 shows the comparison for the global spectral component with the same input parameters and SZAs as Fig. 3. The global irradiance differences at $\mathrm{SZA}=30^{\circ}$ show a slight increase of $1 \%-2 \%$ compared with the $0.5 \%$ 

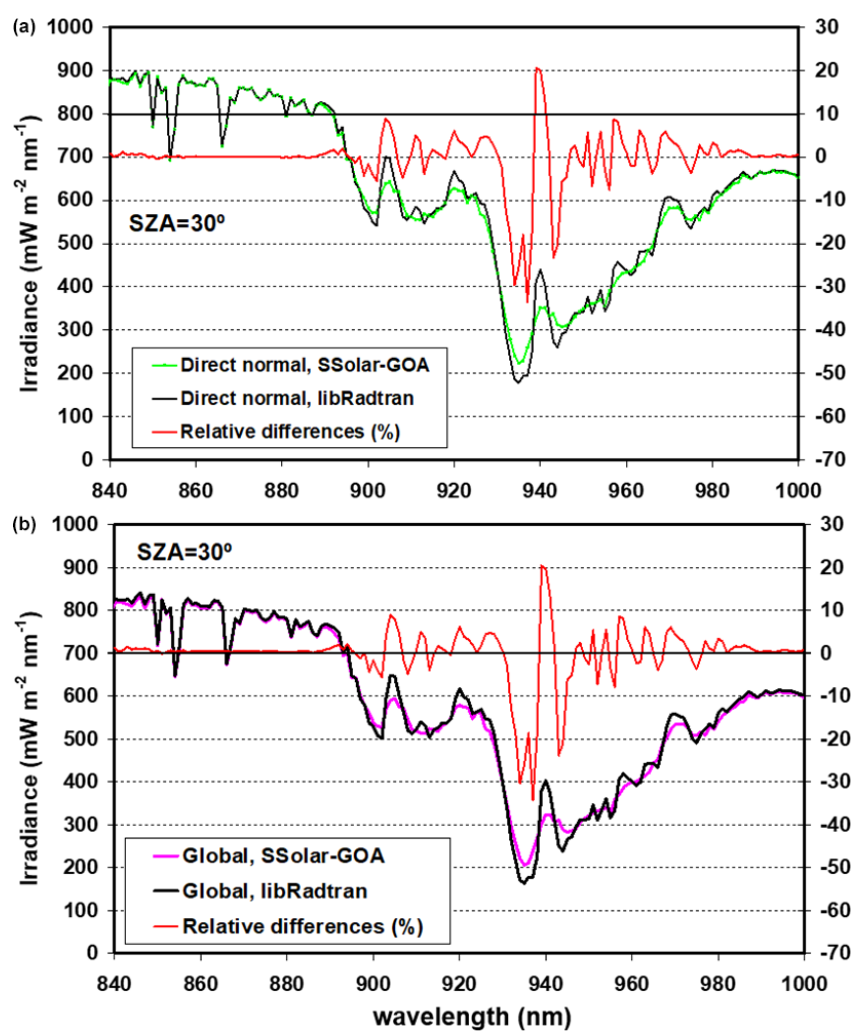

Figure 4. Comparison between libRadtran and SSolar-GOA models in the region of the $940 \mathrm{~nm}$ absorption band of water vapour for direct normal (a) and global (b) solar irradiances at $\mathrm{SZA}=30^{\circ}$.

given by the direct-normal irradiance from $330 \mathrm{~nm}$ to nearly $700 \mathrm{~nm}$ and decreasing for longer wavelengths. The relative differences also decrease with the SZA, and at $\mathrm{SZA}=60^{\circ}$ the relative differences are less than $1 \%$, which is lower than those at 30 and $6^{\circ}$. Relative differences in the regions of the water vapour and oxygen absorption bands show the same variations or features as before. However, a different behaviour in the region of UV ozone absorption band, between $300-320 \mathrm{~nm}$, is observed. The increasing differences range from $0.5 \%$ at $330 \mathrm{~nm}$ to $-25 \%$ at $300 \mathrm{~nm}$ for SZAs of 6 and $30^{\circ}$, but this trend decreases to $10 \%$ for SZA $=60^{\circ}$. This feature does not appear in normal direct irradiance values where a very good agreement was observed, and only the difference very close to $300 \mathrm{~nm}$ increases slightly to $10 \%$ for $\mathrm{SZA}=60^{\circ}$ (Fig. 3). This problem in the ozone UV absorption band (around $300 \mathrm{~nm}$ ) will be discussed later.

Like Figs. 3 and 5, Fig. 6 shows the comparison for the spectral diffuse component. As mentioned, the diffuse component is obtained as the difference between the global and direct components according to Eq. (1). Here, the relative differences in the region of non-gas absorption also increase to reach a maximum of $9 \%$ in the visible and near-infrared range, but this behaviour also decreases at longer wavelengths and with increasing SZA values, with the relative
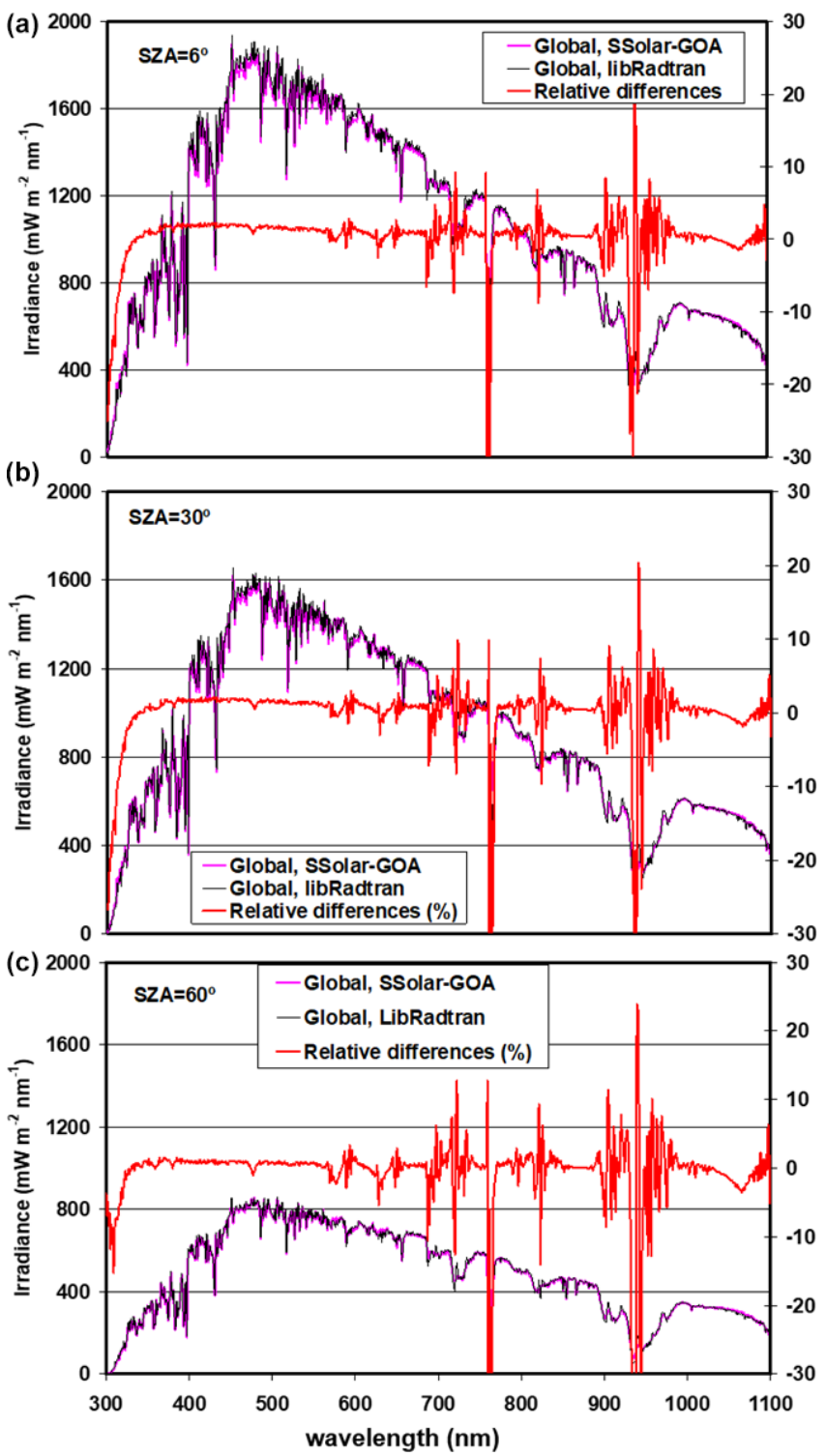

Figure 5. Comparison between libRadtran and SSolar-GOA models for global irradiance at $\mathrm{SZA}=6,30$, and $60^{\circ}$, respectively (from top to bottom), with input parameters shown at the top of Fig. 3. Right $y$ axis indicates the relative differences in percentage ((libRadtran - SSolar-GOA) / libRadtran).

differences ranging from $0 \%-2 \%$ at $\mathrm{SZA}=60^{\circ}$. In general, our model underestimates the diffuse irradiance values for low SZA values in comparison with libRadtran, but there is a good correspondence for the SZA between $40-60^{\circ}$, and thus a better agreement for midlatitudes to low latitudes where these angles are most frequent. The differences are reasonable due to the low diffuse irradiance values under clearsky conditions, which accentuates the relative differences. Moreover, it should be emphasized that there are the different physical approaches used by each model for the determination of the diffuse component. LibRadran directly obtains 
the diffuse irradiance by solving the RT Equation (DISORT solver), while in our model the diffuse component is obtained via the difference between the global and direct-horizontal irradiances.

The problem of the absorption for global irradiance and consequently for diffuse irradiance in the SSolar model in the ozone UV Huggins band may be due to the different treatment of the interaction between scattering and gas absorption. Apart from the above-mentioned procedures for solving the scattering problem (discrete-ordinate/Ambartsumian) libRadtran performed an adequate treatment of the absorptionscattering interaction for the diffuse component (see libRadtran user's guide, 2015, 2020), while our model only performs a simple multiplication of absorption and scattering transmittances. Furthermore, the multilayer approach may have also played an important role in this case. Other possible factors, such as the influence of temperature on the ozone absorption coefficients, seem to have had a minor impact because the direct-normal irradiance does not show these high relative differences. On the other hand, this problem does not appear in the absorption bands of other atmospheric gases or in the Chappuis band of ozone because of the lesser absorption of these bands and their rapid saturation compared to the strong absorption of ozone in the Huggins band. However, considering the strong fall that UV irradiances present close to $300 \mathrm{~nm}$ (over 3 orders of magnitude) and the low irradiance values, the increase to $-30 \%$ of the relative differences (the SSolar model overestimates UV values) is not so big and in part is enhanced with the artifice due to the different spectral resolution of the absorption coefficients of the two models (this always happens in the regions of strong absorption, as observed).

These figures are only a visual snapshot of the extensive comparison between SSolar-GOA and libRadtran where hundreds of spectra were compared covering a wide range of SZA values under the varied atmospheric conditions.

A more quantitative evaluation of this comparison was carried out applying linear regression and the RMSE \% (root mean square error, in percentage) statistical indicator using the earlier solar irradiance values and relative differences. The SSolar-GOA model takes the interval 300 to $2600 \mathrm{~nm}$ as the entire solar range, so this interval was used to apply the linear regression in the comparison between libRadtran and SSolar-GOA for the three SZAs of the earlier figures, as can be seen in Table 1 . As well as this, Table 2 collects the values of the RMSE \% applied to different spectral ranges: UV(300-400 nm), VIS(401-700 nm), NIR(701$1100 \mathrm{~nm})$, and the full shown range $(300-1100 \mathrm{~nm})$. The reason for analysing these four spectral ranges is due to their different behaviour in the comparison and the fact that not taking the entire range $300-2600$ is due to the number of zero values (infinite relative differences) of the irradiance in the water vapour bands existing in the last part of the solar range.
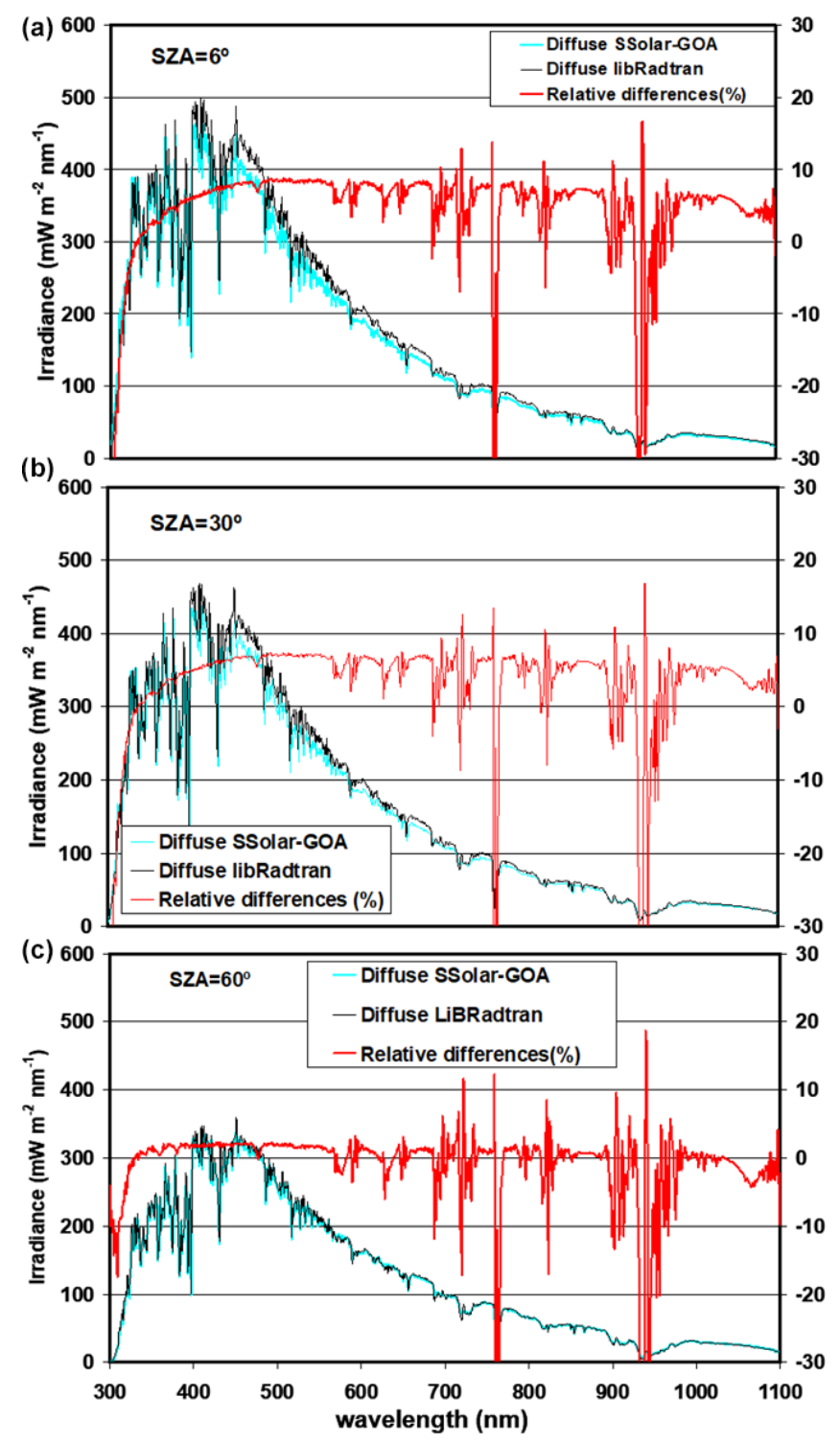

Figure 6. Comparison between libRadtran and SSolar-GOA models for diffuse irradiance at $\mathrm{SZA}=6,30$, and $60^{\circ}$, respectively (from top to bottom), with input parameters shown at the top of Fig. 3 . Right $y$ axis indicates the relative differences in percentage (libRadtran minus SSolar-GOA).

Table 1 shows the slope $(a)$, intercept $(b)$, and correlation coefficient $\left(r^{2}\right)$ for the three SZAs and the three components of solar radiation (it was also added the results for the comparison of measured-modelled data evaluated in the next section). The values of $r^{2}$ are always higher than 0.99 , the slope varies from 1.01 to 1.06 , and the intercept from 0.0005 to $0.013 \mathrm{~W} \mathrm{~m}^{-2} \mathrm{~nm}^{-1}$ (or 0.5 to $13 \mathrm{~mW} \mathrm{~m}^{-2} \mathrm{~nm}^{-1}$ ) for the three SZAs, thus resulting in general a very good agreement. Direct normal and global components have similar slopes, near 1, for the three SZAs, but diffuse components have a worse value $(a=1.06)$ for SZA of 6 and $30^{\circ}$ but im- 
prove to $60^{\circ}$ with a slope of 1.01 , a value similar to the other two components. Intercept $(b)$ values of each case of Table 1 are very low, and they reflect for a given spectrum of a solar component the constant value that the SSolar-GOA model always underestimates the irradiances in relation to libRadtran, but this value of intercept refers to all sets of wavelengths of the whole spectrum. The equivalent information refers to the slope; therefore linear regression is only a relatively good method to know the agreement between the SSolar and libRadtran and more when the $r^{2}$ reaches high values near 1 .

Table 2 gives the values of RMSE \% for the three solar components evaluated for the three SZAs and the four intervals in the solar range (for consistency, it was also added to the results for the comparison of measured-modelled data which will be analysed in the next section). For the visualized range $300-1100 \mathrm{~nm}$ and considering the three SZAs, the values are very similar for direct and global components, varying from $5 \%$ to $8 \%$, but the diffuse component is more stable for the three angles at about $9 \%-10 \%$. Very different values are observed for the other intervals with a clear behaviour for lower $\left(3\right.$ and $\left.30^{\circ}\right)$ or greater SZA $\left(60^{\circ}\right)$. The VIS range stands out for its low values and low variation of the RMSE \% $(0.8 \%-1.6 \%)$ for direct and global components for the three SZAs, increasing for the diffuse component to about $6 \%-8 \%$ for the lower SZA but also decreasing to $2 \%$ for $\mathrm{SZA}=60^{\circ}$. The UV interval presents higher to lower RMSE \% for increasing SZAs, from 6 to $60^{\circ}$, with very different values between the three components: very low values for direct component ( $0.8 \%$ to $2.5 \%$ ), high values for the diffuse ( $11 \%$ to $4.5 \%$ ), and intermediate values for the global component (6.8\%-3.6\%), with a substantial improvement in the comparison for SZA around $60^{\circ}$ for global and diffuse components. Finally, the NIR $=701-1100 \mathrm{~nm}$ interval shows in general higher values of RMSE \% than the other intervals, in this case always increasing with the SZA for the three components. Global and direct components present similar values (from $6 \%$ to $11 \%$ ) and the diffuse component less variation, from $9.7 \%$ to $13 \%$. Summarizing these results, global and direct components present similar numbers for the RMSE \% for the four intervals and a similar behaviour with the SZA but for the UV interval direct normal component present significant lower values. Diffuse component present the highest RMSE \% values, but with a substantial improvement for high SZA, mainly in the UV and VIS ranges. In spite of the valuable information provided by the parameters of the linear regression and the RMSE \%, they do not give detailed information on which wavelengths fail in the compared irradiance spectrum. Therefore, relative differences evaluated across the spectrum together with the evaluation of a large number of spectra are necessary in order to improve the estimated irradiances of the SSolar-GOA model.

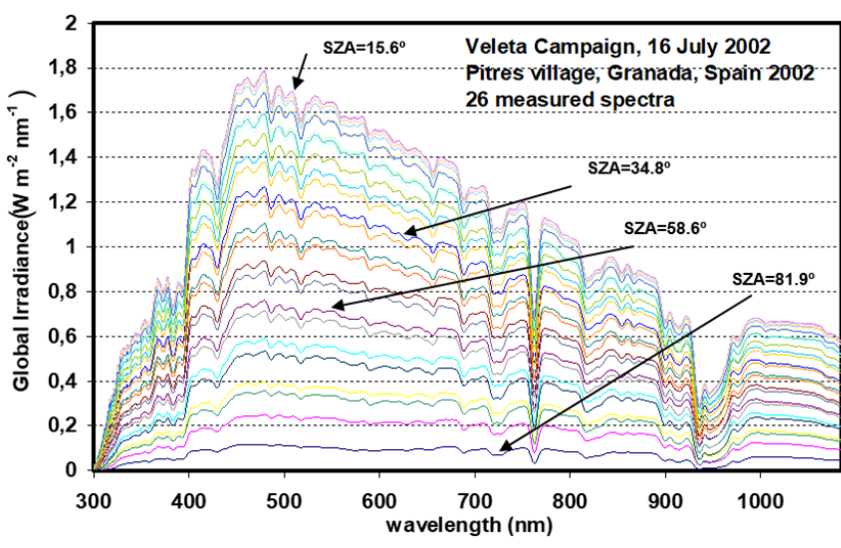

Figure 7. Solar global irradiance spectra measured by LI-1800 during the afternoon of 19 July 2002, during the Veleta campaign at Pitres (Granada, Spain).

\subsection{Comparison between SSolar-GOA and spectral solar irradiance measurements}

To validate the SSolar-GOA model, we selected specific well-suited spectra from our irradiance solar databank. Thousands of solar irradiance spectra have been measured over the past 25 years by GOA for different research activities, most of them focused on atmospheric studies for the determination of atmospheric components (Cachorro et al., 1987b, 1996, 1998, 2000b, a; Vergaz et al., 2005) and modelling of solar spectral radiation. In Cachorro et al. (1985, 1987a, c), one of the first comparisons between field experimental spectral solar irradiance measurements and their modelling with simple spectral solar radiation models can be seen. Detailed radiative transfer models have been also used and compared with experimental spectral solar irradiance data (Cachorro et al., 1997; Durán, 1997; Utrillas et al., 2000; García et al., 2016).

\subsubsection{LI-1800 measured spectra}

A comparison of the SSolar-GOA model and field measurements with the LI-1800 spectroradiometer was carried out as already mentioned. Figure 7 shows 26 spectra of global solar irradiance measured throughout the day of 16 July during the Veleta campaign (Estellés et al., 2006; Alados-Arboledas et al., 2008). This campaign was carried out in July 2002 with the aim of aerosol characterization, making an extensive comparison of aerosol properties retrieved by different instruments, mainly Cimel Sun photometers and LI-1800 spectroradiometers. The campaign was carried out at several locations in the Granada province (Andalusia region, southern Spain). Specifically, the comparison illustrated in Figs. 7 and 8 corresponds to the rural village of Pitres (1300 m a.s.l.) in the Alpujarras region, an area at the southern slope of the Sierra Nevada range.

The validation process requires accurate input model parameters that are not always available, but in our case, they 
Table 1. Linear regression parameters ( $a$ is the slope, $b$ the intercept, and $r^{2}$ the coefficient of determination) applied to the irradiance values of the comparison between SSolar-GOA and libRadtran models for the three solar components and the three SZAs. The same for the day 16 and 19 of Figs. 8 and 9 of the comparison between measured LI-1800 and modelled SSolar-GOA irradiance spectra.

\begin{tabular}{lrrr|rrr|rrrr}
\hline Linear regression & \multicolumn{3}{c}{ GLOBAL } & \multicolumn{3}{c|}{ DIRECT normal } & \multicolumn{3}{c}{ DIFFUSE } \\
\cline { 2 - 9 } & $a$ & $b$ & $r^{2}$ & $a$ & $b$ & $r^{2}$ & $a$ & $b$ & $r^{2}$ \\
\hline $\mathrm{SZA}=6^{\circ}$ & 1.02 & 10 & 0.99 & 1.01 & 10 & 0.99 & 1.06 & 0.0 & 0.99 \\
$\mathrm{SZA}=30^{\circ}$ & 1.02 & 10 & 0.99 & 1.01 & 10 & 0.99 & 1.06 & 0.4 & 0.99 \\
$\mathrm{SZA}=60^{\circ}$ & 1.01 & 7 & 0.99 & 1.02 & 13 & 0.99 & 1.01 & 0.5 & 0.99 \\
Day 16 & 0.98 & 10 & 0.99 & 1.01 & 10 & 0.99 & 0.98 & 9 & 0.94 \\
Day 19 & 1.04 & 9 & 0.99 & 1.0 & 7 & 0.99 & 1.21 & 10 & 0.99 \\
\hline
\end{tabular}

Table 2. RMSE in percentage (\%) evaluated in the comparison between SSolar-GOA and libRadtran models for the three solar components and the three SZAs. The same for the day 16 and 19 of Figs. 8 and 9 of the comparison between measured LI-1800 and modelled SSolar-GOA irradiance spectra.

\begin{tabular}{lrrrr|rrr|rr|rrrr}
\hline \multirow{2}{*}{ RMSE \% } & \multicolumn{4}{c}{ GLOBAL } & \multicolumn{3}{c|}{ DIRECT normal } & \multicolumn{4}{c}{ DIFFUSE } \\
\cline { 2 - 11 } & UV & VIS & NIR & FULL & UV & VIS & NIR & FULL & UV & VIS & NIR & FULL \\
\hline SZA =6 & 6.3 & 1.6 & 6.6 & 5.3 & 0.8 & 0.8 & 6.6 & 4.6 & 11. & 7.6 & 9.7 & 9.3 \\
$\mathrm{SZA}=30^{\circ}$ & 6.8 & 1.5 & 7.4 & 5.8 & 0.9 & 0.9 & 7.2 & 5.1 & 11. & 6.3 & 10.0 & 8.9 \\
$\mathrm{SZA}=60^{\circ}$ & 3.6 & 1.4 & 11.2 & 8.0 & 2.5 & 1.3 & 11 & 7.9 & 4.5 & 2.0 & 13.3 & 9.6 \\
Day 16 & 12 & 1.5 & 4.7 & 5.7 & 9.9 & 1.6 & 5.0 & 5.1 & 16 & 16 & 34 & 26 \\
Day 19 & 18 & 5.4 & 5.7 & 8.3 & 11 & 1.6 & 5.0 & 5.6 & 37 & 26 & 66 & 51 \\
\hline
\end{tabular}

were provided by various Cimel Sun photometers installed for the Veleta 2002 campaign (as explained in Estellés et al., 2006 and Alados-Arboledas et al., 2008). The water vapour content was provided by one of these Cimel Sun photometers connected to AERONET. The ozone vertical content was obtained by the daily values provided by the TOMS satellite sensor. Due to the error associated with the determination of the $\beta$ turbidity parameter and the fact that AERONET did not provide it, the value of this parameter was replaced by the aerosol optical depth at $1020 \mathrm{~nm}$. Since Cimel and LI1800 measurements are not exactly coincident in time, the closer measured values or the interpolated data in between were taken. The aerosol single scattering albedo $\left(\omega_{\mathrm{a}}\right)$ and the asymmetry parameter $\left(g_{\mathrm{a}}\right)$ were taken as constant with the wavelength, as a first simple approach to the modelling as explained above. The value of $g_{\mathrm{a}}$ was taken as an average of 0.65 for that day, as was $\omega_{\mathrm{a}}$, which had a value of 0.99 (both values were provided by AERONET). These two values are reasonable for non-absorbing aerosols, such as those characteristics of clean rural areas such as Pitres. All these values of the input model parameters appear in Fig. 8 in order to model the three components of solar radiation.

Figure 8 corresponds to 16 July of Veleta Campaign, where the direct normal and global horizontal components were measured 2 min apart: at 11:28 GMT for direct normal component and 11:30 GMT for the global component,

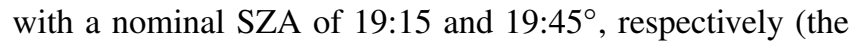
air mass values were 1.057 and 1.061, respectively). Bear in mind that the LI- 1800 takes about $40 \mathrm{~s}$ to measure a spectrum from $300-1100 \mathrm{~nm}$, and we assign a unique time value for the measured spectrum. Therefore, the time difference between direct and global spectra is non-significant in terms of modelling. An excellent agreement is obtained between measured-modelled data for direct normal irradiance values, with relative differences ranging from $1 \%$ to $3 \%$ in the visible range $(400-700 \mathrm{~nm})$ and less than $10 \%$ in other spectral ranges. RMSE \% of Table 2 gives a $5.1 \%$ for the 300$1100 \mathrm{~nm}, 1.6 \%$ for the VIS, and $9.9 \%$ for the UV range, and Table 1 gives 1.01 for the slope, $11 \mathrm{~mW} \mathrm{~m}^{-2} \mathrm{~nm}^{-1}$ for the intercept, and 0.99 for $r^{2}$. We have used the spectrum of Wehrli (Wehrli, 1985) convoluted with the spectroradiometer slit function represented by a triangular function of $7 \mathrm{~nm}$ FWHM since the original file has a spectral resolution of $1 \mathrm{~nm}$. We call attention to the observed lesser differences of the already-mentioned oxygen and water vapour bands because of the similar spectral resolution between our model and the measured data from the LI-1800 in relation to the above comparison with libRadtran. The observed differences around $1100 \mathrm{~nm}$ are due to a specific problem of heating in the LI-1800 spectroradiometer (bear in mind that this instrument is not thermally stabilized). The temperature in Pitres in July reached up to $35^{\circ} \mathrm{C}$, but this problem disappears for lower temperatures.

Similar results were obtained in the comparison of the global irradiance spectrum in this case and whose statistical indicators are listed in the Tables 1 and 2. Diffuse irradi- 

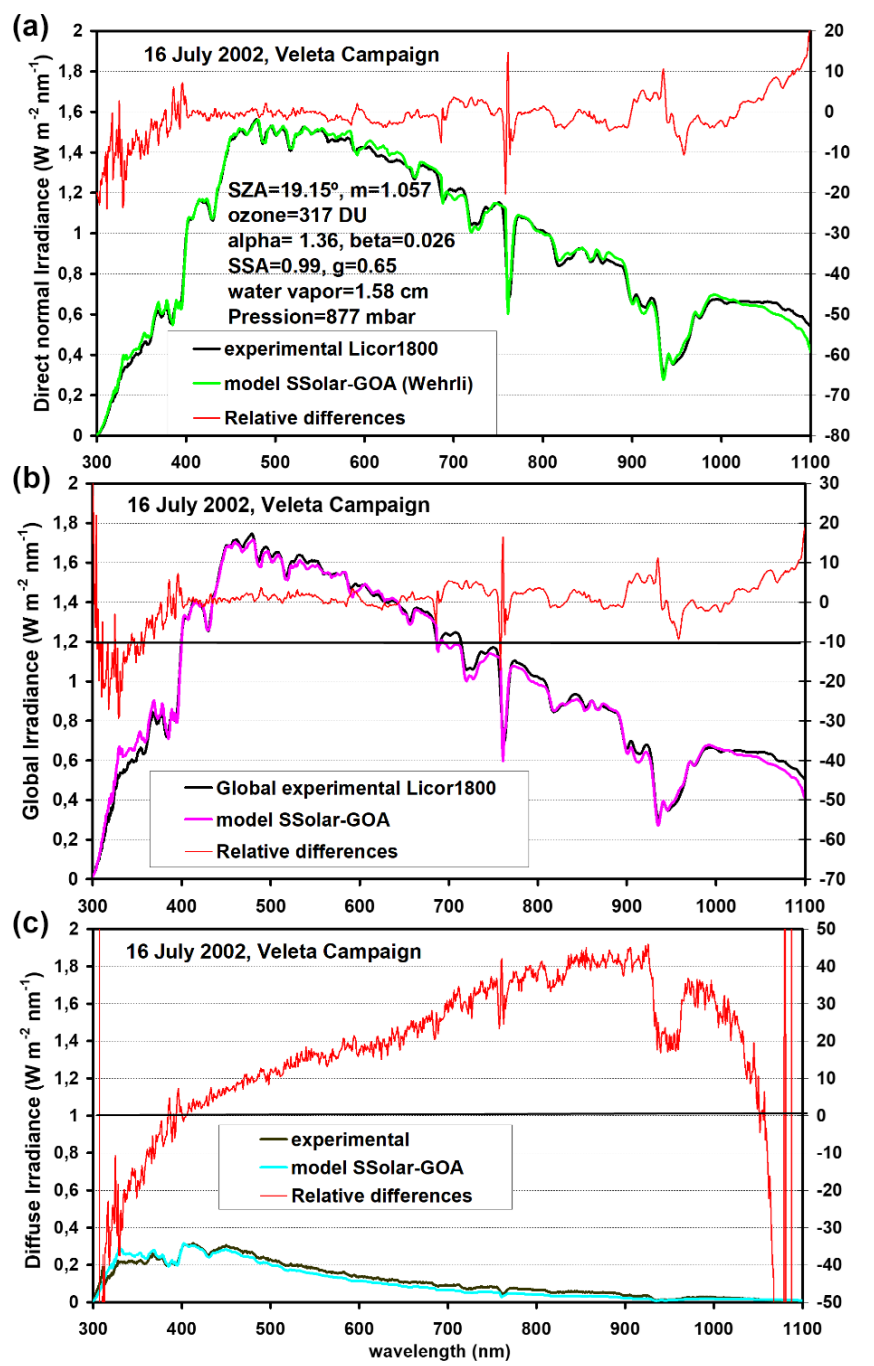

Figure 8. Comparison between the LI-1800 measurements and the SSolar-GOA model for direct, global, and diffuse spectral irradiances (from top to bottom) for 16 July 2002, at Pitres (Granada, Spain). The input parameters are specified at the top. Right $y$ axis indicates the relative differences (\%, in red colour) of measured minus modelling data (only for the output data taken from the Wehrli spectrum).

ances show greater disagreement with underestimated values for the infrared and overestimated values for UV and good agreement around $400 \mathrm{~nm}$. The differences range from $-40 \%$ to $40 \%$, the slope of the linear correlation is 0.98 , and the $r^{2}$ falls to 0.94 . The RMSE \% for the whole measured spectral range is $5.7 \%$ with low values in the VIS and higher values in the UV and NIR as can be seen in Table 2. However, considering the low values of diffuse irradiances for clear skies and the associated uncertainty, it can be said that these differences are in reasonable concordance. As already mentioned, both the measured and the modelled diffuse irradiance values were obtained as the difference between the global irradiance and the horizontal direct irradi- ance, where uncertainties are added. The approach of assuming an isotropic model to evaluate the horizontal direct spectral irradiance (bear in mind the factor given by $\cos (\mathrm{SZA})$ ) entails a high uncertainty that is difficult to assess, and that is more pronounced considering that Pitres is on the slopes of the Sierra Nevada.

Figure 9 corresponds to 19 July where direct normal and global components were measured $2 \mathrm{~min}$ apart: at 13:26 GMT for direct normal component and at 13:28 GMT for the global component, with a nominal SZA of 21.63 and 21.92, respectively (the air mass values were 1.075 and 1.077, respectively). The value of alpha $=0.69$ and SSA $=0.97$ parameters corresponded to a desert dust aerosol type, since a low-moderate intrusion of desert-dust arrived to this area on 19 July. Table 1 reports 1.0 for the slope, $7 \mathrm{~mW} \mathrm{~m}^{-2} \mathrm{~nm}^{-1}$ for the intercept, and 0.99 for $r^{2}$, and Table 2 gives a RMSE \% of $5.6 \%$ for the $300-1100 \mathrm{~nm}$ and $11 \%, 1.6 \%$, and $5 \%$ for the UV, VIS, and NIR spectral ranges respectively. Therefore, the modelled direct normal irradiance shows a very good agreement with the measured data as shown earlier in Fig. 8, but in Fig. 9 we have also added the simulated output irradiance taken for the Gueymard (Gueymard, 2004) extraterrestrial spectrum (it was also convoluted as before the Wehrli, 1985, spectrum). In this case, some slight differences can be observed between experimental and modelled irradiances between 400 and $500 \mathrm{~nm}$.

These differences are due to the differences in the original extraterrestrial spectra, as can be seen in Fig. 10, where both spectra are compared and where the well-known $\mathrm{Ku}-$ rucz extraterrestrial spectrum was also added to strengthen the comparison. The differences between Wehrli and Gueymard spectra in terms of quantity are around $\pm 5 \%$ as maximum, due to the spectral variability in the UV-Visible region $(300-500 \mathrm{~nm})$ if compared to the smoother behaviour in the infrared. However, both spectra present greater relative differences to the Kurucz spectrum, with positive and negative values that reach a maximum of $10 \%-15 \%$ in the $300-$ $500 \mathrm{~nm}$ region. Therefore, it is important to note the observed differences between the solar models and spectral measurements due to the uncertainty associated with the different extraterrestrial spectra.

Modelled global irradiance for 19 July shows greater values than measured ones with differences around $5 \%$ in the visible region, which are greater than those on 16 July. As expected, diffuse irradiances also show important differences with a higher overestimation of modelled data derived from the earlier overestimation of global spectral data. However, we can observe the different spectral behaviour shown by the relative differences on days 16 and 19. Day 19 presents more stable behaviour with negative differences always ranging from $20 \%$ to $40 \%$. Certainly, diffuse modelled data do not present a good agreement for low SZA angles, but an improvement is found for higher SZAs (see the next section). The RMSE \% and parameters of linear regression for these two solar components can be also seen in Tables 1 and 

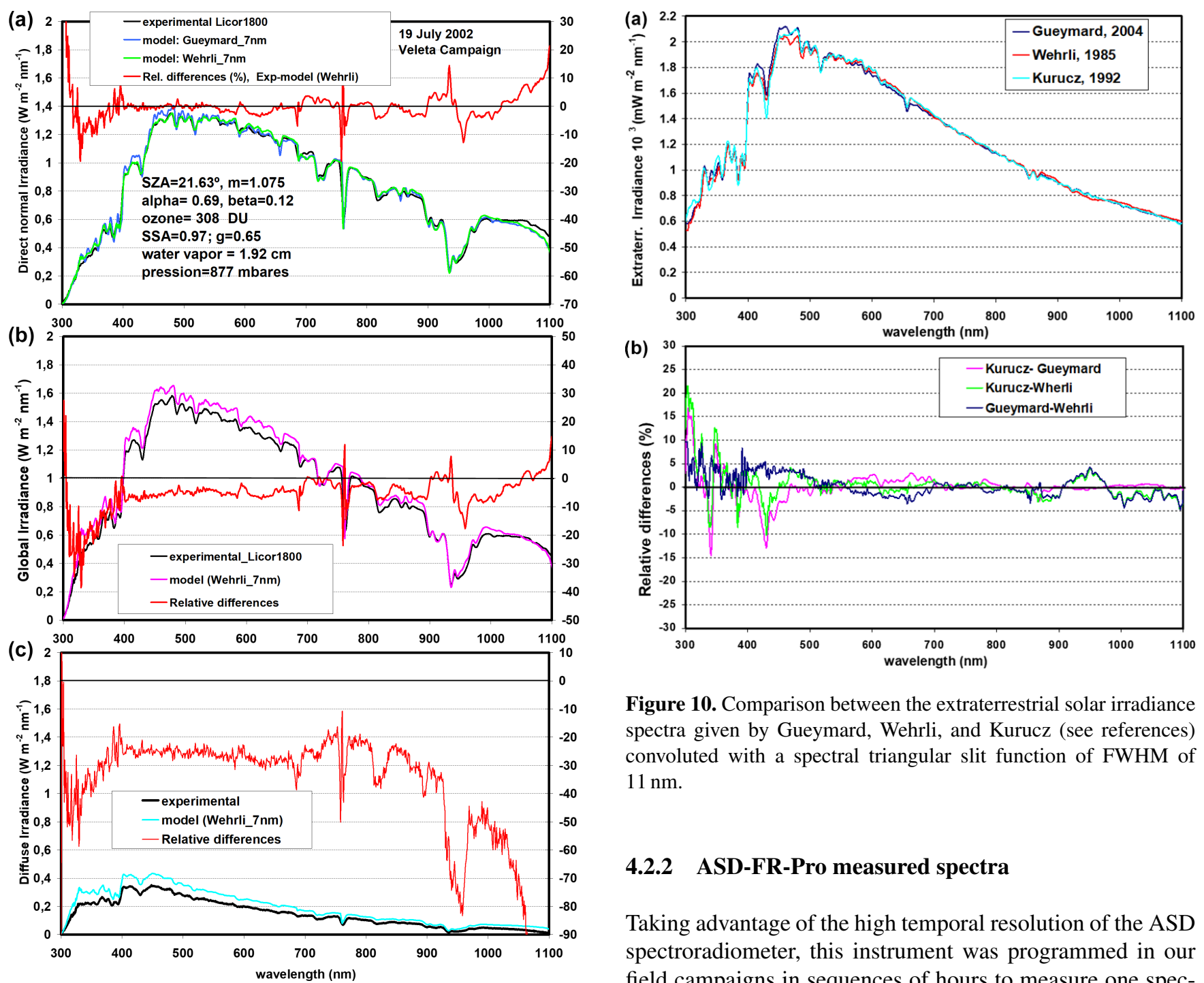

Figure 10. Comparison between the extraterrestrial solar irradiance spectra given by Gueymard, Wehrli, and Kurucz (see references) convoluted with a spectral triangular slit function of FWHM of $11 \mathrm{~nm}$.

\subsubsection{ASD-FR-Pro measured spectra}

Taking advantage of the high temporal resolution of the ASD spectroradiometer, this instrument was programmed in our field campaigns in sequences of hours to measure one spectrum (from 350 to $2500 \mathrm{~nm}$ ) every minute. A set of 890 global solar spectra were measured throughout the day of 29 July 2008, at the site of Andenes on Andøya Island in the Verterålen Archipelago in Norway. Because of the great number of spectra, we selected different wavelengths and observed their behaviour throughout the day. Figure 11a shows the measured (dark-blue points) and modelled (continuous green line) global irradiance values at the wavelength of $440 \mathrm{~nm}$ as a function of GMT. The values of global irradiance at $440 \mathrm{~nm}$ are drawn from each measured spectrum. To generate the modelled values, a constant aerosol optical depth throughout the day of AOD $(440 \mathrm{~nm})=0.14$ was considered, in accordance with the mean value of the day and the behaviour of the aerosol optical depth during the day. To be precise, Fig. 12 shows the time evolution of AOD at different wavelengths and the alpha parameter on 29 July measured by the Cimel Sun photometer of the Andenes-AERONET station.

Therefore, in order to account for the variability of the AOD during the day, we have taken these values as the input 

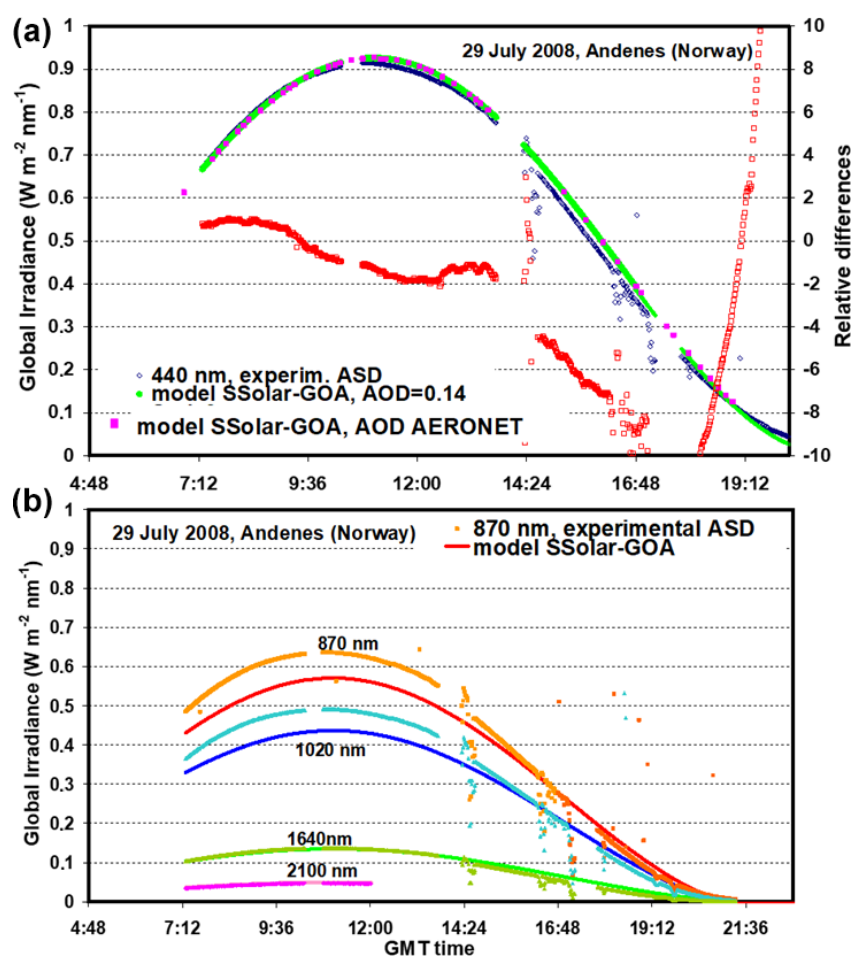

Figure 11. Comparison between the ASD measurements (dark blue line) and the SSolar-GOA model (green line) for the global spectral irradiance at $400 \mathrm{~nm}$ as a function of GMT on 29 July 2008, at Andenes (Andøya Island, Norway). The rose points overlapping the green line are also modelled points at the specific time, and the AOD values are given by AERONET Cimel Sun photometer. At the bottom graph, the lines also give measured and modelled global irradiance values for different wavelengths (orange-red is $870 \mathrm{~nm}$, light and dark blue is $1020 \mathrm{~nm}$, dark and light green is $1640 \mathrm{~nm}$, dark and light rose is $2100 \mathrm{~nm}$ ).

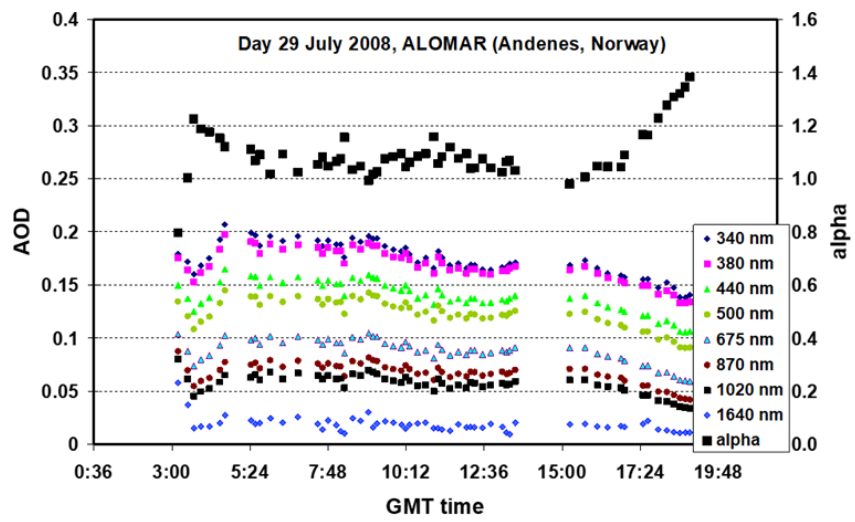

Figure 12. Time evolution of AOD at different wavelengths and alpha parameter on 29 July 2008 at Andenes (Andøya, Norway).

in the model resulting in rose points, just over the green line. In addition to the aerosol parameter provided by AERONET, ozone and water vapour content were also taken from the AOD file of AERONET (level 2, quality assured). The good agreement demonstrates the low variability of AOD throughout the day and the correct approach for a fixed AOD value for modelling the entire day. A very good agreement is obtained with relative differences (ranging about $\pm 2 \%$ ) in most of the central hours of the day and falls to $-10 \%$ thereafter, wherein the SZA reaches values close to $90^{\circ}$ and the relative mass reaches the value of 40 (at these points, the relative differences grow rapidly because of the very low irradiance values).

The observed scattered points are due to clouds, because the measured spectra are not screened. Usually if significant cloudiness was observed, the system was stopped, but often the observed breakdown in the line of global measured values is because the ASD system was also arranged to measure the zenith radiance. During the day, we alternated some periods to measure the global irradiance and others to measure the zenith radiance, but on day 29 most of the measured values were of global solar irradiance.

At the bottom of Fig. 11, a similar graph is shown but for the wavelengths of non-absorption of 800, 1020, 1640, and $2100 \mathrm{~nm}$. For the $800 \mathrm{~nm}$ wavelengths, the orange points are the measured values and the red line contains the modelled values. The same is true for the $1020 \mathrm{~nm}$ (light blue points measured and a dark blue modelled line), $1640 \mathrm{~nm}$ (dark green points measured and a light green modelled line), and $2100 \mathrm{~nm}$ (rose points measured and a light rose modelled line) wavelengths. As stated above, the modelling was carried out with a fixed AOD value at each specific wavelength taken from the AERONET data according to Fig. 12. While longer wavelengths of 1640 and $2100 \mathrm{~nm}$ show a perfect agreement between the measured and modelled values at $400 \mathrm{~nm}$, the other two wavelengths in the near-infrared range, 870 and $1020 \mathrm{~nm}$, give a greater disagreement of about $10 \%$ $12 \%$ in the interval of time around the central hour of the day and decrease at 16:00 GMT. For a better visualization of this in Fig. 11, the values after 12:00 GMT at the $2100 \mathrm{~nm}$ wavelength have not been drawn, but this wavelength also gives a perfect concordance.

These observed differences at these infrared wavelengths may be due to different causes: (a) there is an error much greater than usual due to ASD calibration at these wavelengths; (b) for global radiation measurements, special care must be taken with the horizontal levelling of the cosine receptor sensor, taking into account that this platform is moving for the alternate zenith radiance measurements; (c) the error linked to the modelling refers to the complete and perfect curvature of the modelled spectra of solar irradiance, which is not easy, and even less so if we model a wide spectral range. The curvature of the irradiance spectrum is governed by the shape of the curvature of the AOD, that is, by the dependence of AOD on wavelength. In our modelled values, this curvature is constructed by the pair of values from the Ångström $\alpha-\beta$ turbidity parameters, which only gives a linear behaviour on the plot of $\log$-AOD versus $\log -\lambda$, while real aerosols showed an accentuated curvature on this type of 
plot. Nevertheless, the modelling can be improved by taking two pairs of $\alpha-\beta$ values applied to different spectral intervals or by taking 5-6 values of measured AOD, but all this entails more complicated input model parameters. For example, the alpha-beta values determined in the visible region are not recommended to be applied in the UV region. It is easy to observe how in our model the UV region presents greater relative differences than other parts of the spectrum when considering non-gas-absorption regions.

However, more similar measured-modelled values would be expected in Fig. 11, bearing in mind that the modelling at these selected wavelengths is more accurate than the modelling of the entire spectrum, because in this case it contains the exact AOD value at these wavelengths. As well as this, in the above comparison with the LI-1800, we have also often observed these differences between measured-modelled values for global irradiances of about $10 \%-15 \%$. Therefore, an error in modelling added to calibration errors can reach these values.

Figure 13 shows the measured and modelling values of three specific spectra on $29 \mathrm{July}$, from 350 to $2200 \mathrm{~nm}$, at SZAs of 50.86, 67.29, and 82.59, respectively. The three spectra show a slightly different agreement with the modelled data. A notable disagreement is observed between the measured-modelled spectrum at 10:48 GMT $(\mathrm{SZA}=50.86)$, with relative differences reaching $10 \%-15 \%$. Spectra at SZAs of 67.29 and 82.59 show a better concordance, with relative differences of about $2 \%-10 \%$. These are the same results observed in Fig. 11 when analysing discrete selected wavelengths throughout the day, but now giving the overall behaviour of the whole spectrum. Certainly, the spectrum at $\mathrm{SZA}=82.59(m=7.3)$ represents an extreme situation with very low spectral irradiance values, which may be of interest for some applications, such as the determination of the amount of absorbing gas. However, these cases are of little interest in solar energy resources at middle latitudes, but not negligible in very low latitudes since there are a large number of hours with this insolation.

\section{Discussion and conclusions}

Despite the abundant research about solar radiation models, there exists a broad gap between the different research communities that develop and use or apply solar radiation models (i.e. between the models used by the solar energy community, satellite remote sensing, or in the same climate-atmosphere area). Certainly, each community has its own necessities and objectives and hence solar radiation models may be used for many distinct applications. On the other hand, the number of different methodologies developed to solve the process of scattering and absorption of atmospheric components, from complicated methods to simple approaches, constitutes a rich and varied field of study. The solar energy community mainly develops and applies solar radiation models based on empiri-

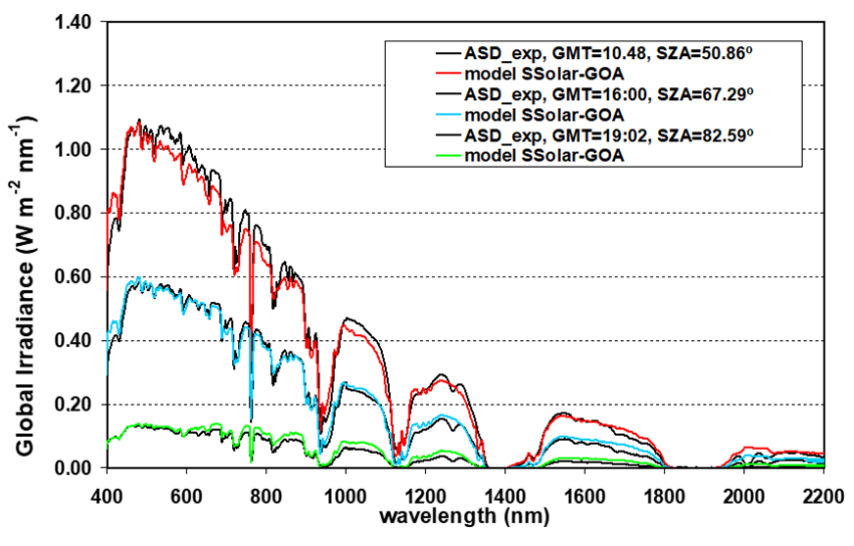

Figure 13. Comparison between the ASD measured and modelled SSolar-GOA global irradiance spectra covering the spectral range from 350 to $2200 \mathrm{~nm}$, taken on 29 July 2008 at Andenes (Andøya, Norway) at three SZAs. Input aerosol parameters are obtained from the values shown in Fig. 12 (see text).

cal expressions fitted on measured solar radiation data, while in the climate-atmosphere field a more theoretical-physical foundation is contained in the radiation models. Therefore, this work seeks to decrease this gap so that potential users who are not very familiar with radiative transfer theory can make use of solar physical radiation models if they are presented under simple parameterized expressions, based on a set of input parameters easy to use and understand.

The evaluation of the diffuse component is generally a more complicated problem, and most of the models are based on the solution of the RTE for the scattering process. However, here RTE solving is replaced by a different methodology developed by Ambartsumian and represented by an uncomplicated analytical function which expresses the transmittance of total scattering of a mixed molecule-aerosol layer, which is really the core of the model. Although this analytical transmittance is a function of more unknown aerosol parameters, such as the single scattering albedo and the parameter of asymmetry, the aerosol optical depth is the most relevant parameter which drives the model, and this is provided in many sites around the world by AERONET network.

The SSolar-GOA model is structured based on a single layer for the entire atmosphere, and therefore the evaluation of solar irradiances must be made at the bottom surface but the altitude of this surface is not necessarily the ground level; it may be defined by the user (e.g. on top of a mountain, the flight level of an aeroplane, or the sea surface) but taking into account the adequate input parameters. The method of Ambartsumian also evaluated the reflectance of the mixed layer of molecules and aerosols, and this new magnitude will be considered in further development of the SSolar-GOA model, extending it to other possible applications, mainly in flight platforms and satellite remote sensing areas.

On the other hand, to take a unique atmospheric layer instead of multiple layers is not a great handicap for the es- 
timation of solar irradiances under clear skies if their evaluation is based on the LBL approach. The main contribution to global solar irradiance at the lower level surface under clear skies is given by the direct component, where its contribution is about $80 \%-62 \%$ for the SZA in the range from 20 to $70^{\circ}$ under current atmospheric conditions of aerosol load $(\sim \operatorname{AOD}(500 \mathrm{~nm})=0.1)$ and water vapour content $(\sim 1.5 \mathrm{~cm})$, these two atmospheric components being the most influential.

The direct normal spectral component based on the LBL law and expressed as the product of exponential function transmittances results in concise and computationally undemanding formulation. Importantly, it was shown that the assumption of a single layer of aerosols and molecules instead of the multiple-layer atmosphere does not have significant influence over the calculated values of the spectral solar direct irradiance, thanks to these exponential functions that drive the absorption and scattering processes. The multiplication of exponential function is equivalent to the sum of its exponents and the total optical thickness of the whole atmospheric layer is the sum of the multiple layers, and hence the same value is obtained. Although this fails for gas absorption because of the dependence on absorption coefficients on pressure and temperature, the difference in spectral irradiance values is not relevant when we want to estimate solar radiation at ground level, as it is for those measured by our spectroradiometers, or for many applications in solar energy, agriculture, forest and ecology, where an accuracy about 5\%-10\% may be sufficient.

Depending on the required level of accuracy for the solar spectral irradiances, the SSolar-GOA model can provide them as input variables in other radiative transfer models applied to vegetation studies, such as the SAIL and PROSAIL models (Jackemoud et al., 2009; Berjón et al., 2013), or as part of sub-models in the new Earth system models (ESMs), as SCOPE (Yang et al., 2021) or CliMA (Braghiere et al., 2021). Solar radiative transfer models applied to vegetation to retrieve biophysical plant parameters not only share many methods and concepts with RT models developed for the atmosphere, but they are joined or combined when satellite remote sensing data are acquired for this objective.

Climate models and forecast weather models (Sukhodolov et al., 2014) do not use spectral solar radiation models because they need a rapid evaluation which is covered by the "integrated or broad-band" solar radiation models, although many of them consider the entire solar spectrum to be divided into various intervals or spectral bands using the $K$ correlation method as the most common way to account for the absorption of gases. Therefore, in this area of application the SSolar-GOA model may be useful as a rapid test of these "broad-band" models since it also gives as output the integrated values of the irradiances for the three components. The inclusion of an effective plane-parallel cloud layer is also a feasible possibility taken as a parameterized cloud scheme (Liou, 1992), which can increase the potential of the SSolar-
GOA model, but it must be kept in mind that the SSolar-GOA model was designed as a simple clear-sky model, easy to use, which cannot to compete with multilayer RT codes that solve the RT equation. To the authors' knowledge it is not easy to find in the literature a spectral model of similar characteristics, the most similar being the SMART model (see the recent publication of Gueymard, 2019, about the variety of applications where this model has been used in the last 20 years).

The performance of the SSolar-GOA model is clearly demonstrated by the comparative task with the libRadtran model, where a very good agreement is obtained. Both are based on a similar evaluation of the direct component thanks to the LBL law. The discrepancies in the diffuse solar spectral component are mainly due to the different theoretical treatments of the interaction of scattering-absorption processes between both models. Certainly, the comparison with experimental data does not reach the same level of agreement as before, but it highlights the difficulty of spectral solar radiation measurements. The proposed model has a strong physical base and due to its simplicity, accuracy, and rapid runtime it is well suited to evaluate the three components of the spectral solar radiation data - today required by many different applications - and is therefore open to very different types of users.

Code and data availability. The SSolar-GOA model version 1.0 is open-source and can be accessed at a DOI repository: https://doi.org/10.5281/zenodo.5796545 (Cachorro et al., 2021). This code has GNU General Public License v2.0 or later. The dependencies and install instructions are in a readme file. For windows users a binary package has been generated which can be downloaded from http://goa.uva.es/ssolar_goa-model// (last access: 15 December 2021).

Author contributions. The model was designed, developed, and evaluated by VEC (with the first software versions in FORTRAN). Spectroradiometer calibration and maintenance was performed by AMdF. Measurements were carried out by the different members of the GOA-UVa team over the last 25 years. JCAS makes the current final software version of the model and the internet platform for users. VEC wrote the paper, and JCAS prepared the final paper for journal submission. All authors have read and agreed to the published version of the paper.

Competing interests. The contact author has declared that neither they nor their co-authors have any competing interests.

Disclaimer. Publisher's note: Copernicus Publications remains neutral with regard to jurisdictional claims in published maps and institutional affiliations. 
Acknowledgements. The authors gratefully thank AERONET/RIMA for the aerosol products, ALOMAR Laboratory (Andøya Space Centre, Andenes, Norway), and the GOA-UVA team for the spectral solar radiation measurements and all kinds of help. Special thanks to all people who took part in the "Veleta 2002 campaign". Special thanks to Rosa D. García of the Izaña Atmospheric Research Center (AEMET) for its valuable contribution to the simulations with the libRadtran and SSolar-GOA models. The first current software version of the SSolar-GOA model in Python was built by Victor Molina García (currently at DLR, Oberpfaffenhofen, Germany).

Financial support. This research has been supported by "Ministerio de Ciencia e Innovacion” (grant no. RT2018-097864-B-I00) and “Junta de Castilla y León” (grant no. VA227P20).

Review statement. This paper was edited by Sylwester Arabas and reviewed by Nina Crnivec and one anonymous referee.

\section{References}

Alados-Arboledas, L., Alcántara, A., Olmo, F. J., Martínez-Lozano, J. A., Estellés, V., Cachorro, V., Silva, A. M., Horvath, H., Gangl, M., Díaz, A., Pujadas, M., Lorente, J., Labajo, A., Sorribas, M., and Pavese, G.: Aerosol columnar properties retrieved from CIMEL radiometers during VELETA 2002, Atmos. Environ., 42, 2654-2667, https://doi.org/10.1016/j.atmosenv.2007.10.006, 2008.

Amillo, A., Huld, T., Vourlioti, P., Müller, R., and Norton, M.: Application of Satellite-Based Spectrally-Resolved Solar Radiation Data to PV Performance Studies, Energies, 8, 3455-3488, https://doi.org/10.3390/en8053455, 2015.

Amoruso, A., Cacciani, M., Sarra, A. D., and Fiocco, G.: Absorption cross sections of ozone in the 590- to 610 -nm region at $\mathrm{T}$ $=230 \mathrm{~K}$ and $\mathrm{T}=299 \mathrm{~K}$, J. Geophys. Res.-Atmos., 95, 2056520568, https://doi.org/10.1029/JD095iD12p20565, 1990.

Anderson, S. M. and Mauersberger, K.: Laser measurements of ozone absorption cross sections in the Chappuis Band, Geophys. Res. Lett., 19, 933-936, https://doi.org/10.1029/92GL00780, 1992.

Ångström, A.: On the Atmospheric Transmission of Sun Radiation and on Dust in the Air, Geogr. Ann., 11, 156-166, https://doi.org/10.1080/20014422.1929.11880498, 1929.

Ångström, A.: On the Atmospheric Transmission of Sun Radiation. II, Geogr. Ann., 12, 130-159, https://doi.org/10.1080/20014422.1930.11880522, 1930.

Ångström, A.: Techniques of determine the turbidity of the atmosphere, Tellus, 13, 214-223, https://doi.org/10.3402/tellusa.v13i2.9493, 1961.

Ångström, A.: The parameters of atmospheric turbidity, Tellus, 16, 64-75, https://doi.org/10.1111/j.2153-3490.1964.tb00144.x, 1964.

ASD Full Range, Portable Spectrometers \& Spectroradiometers | Malvern Panalytical: https://www.malvernpanalytical.com/en/ products/product-range/asd-range, last access: 30 March 2021.
Bais, A., Blumthaler, M., Webb, A., Seckmeyer, G., Thiel, S., Kazadzis, S., Redondas, A., Kift, R., Kouremeti, N., Schallhart, B., Schmitt, R., Pisulla, D., Diaz, J. P., Garcia, O., Diaz Rodriguez, A. M., and Smedley, A.: Intercomparison of solar UV direct irradiance spectral measurements at Izana in June 2005, Optics \& Photonics 2005, San Diego, California, USA, 588609, https://doi.org/10.1117/12.619925, 2005.

Bass, A. M. and Paur, R. J.: The Ultraviolet Cross-Sections of Ozone: I. The Measurements, in: Atmospheric Ozone, edited by: Zerefos, C. S. and Ghazi, A., Springer, Dordrecht, https://doi.org/10.1007/978-94-009-5313-0_120, 1985.

Berjón, A. J., Cachorro, V. E., Zarco-Tejada, P. J., and de Frutos, A.: Retrieval of biophysical vegetation parameters using simultaneous inversion of high resolution remote sensing imagery constrained by a vegetation index, Precis. Agric., 14, 541-557, https://doi.org/10.1007/s11119-013-9315-8, 2013.

Bird, R. E.: A simple, solar spectral model for direct-normal and diffuse horizontal irradiance, Sol. Energy, 32, 461-471, https://doi.org/10.1016/0038-092X(84)90260-3, 1984.

Bird, R. E. and Riordan, C.: Simple Solar Spectral Model for Direct and Diffuse Irradiance on Horizontal and Tilted Planes at the Earth's Surface for Cloudless Atmospheres, J. Appl. Meteorol. Climatol., 25, 87-97, https://doi.org/10.1175/15200450(1986)025<0087:SSSMFD>2.0.CO;2, 1986.

Bodhaine, B. A., Wood, N. B., Dutton, E. G., and Slusser, J. R.: On Rayleigh Optical Depth Calculations, J. Atmos. Ocean. Tech., 16, 1854-1861, https://doi.org/10.1175/15200426(1999)016<1854:ORODC>2.0.CO;2, 1999.

Bohren, C. F. and Huffman, D. R.: Absorption and Scattering of Light by Small Particles, WILEY-VCH Verlag GmbH \& Co. KGaA, https://doi.org/10.1002/9783527618156, 1998.

Braghiere, R. K., Wang, Y., Doughty, R., Sousa, D., Magney, T., Widlowski, J. L., Longo, M., Bloom, A. A., Worden, J., Gentine, P., and Frankenberg, C.: Accounting for canopy structure improves hyperspectral radiative transfer and sun-induced chlorophyll fluorescence representations in a new generation Earth System model, Remote Sens. Environ., 261, 112497, https://doi.org/10.1016/j.rse.2021.112497, 2021.

Brion, J., Chakir, A., Charbonnier, J., Daumont, D., Parisse, C., and Malicet, J.: Absorption Spectra Measurements for the Ozone Molecule in the 350-830 nm Region, J. Atmos. Chem., 30, $291-$ 299, https://doi.org/10.1023/A:1006036924364, 1998.

BSRN: Baseline Surface Radiation Network: https://bsrn.awi.de/, last access: 30 March 2021.

Cachorro, V. E. and Salcedo, L. L.: New Improvements for Mie Scattering Calculations, J. Electromagn. Waves Appl., 5, 913926, https://doi.org/10.1163/156939391X00950, 1991.

Cachorro, V. E., de Frutos, A. M., and Casanova, J. L.: Comparison between various models of solar spectral irradiance and experimental data, Appl. Optics, 24, 3249-3253, https://doi.org/10.1364/AO.24.003249, 1985.

Cachorro, V. E., de Frutos, A. M., and Casanova, J. L.: Determination of total vertical water vapor in the atmosphere, Atmos. Res., 20, 67-74, https://doi.org/10.1016/0169-8095(86)90008-6, 1986.

Cachorro, V. E., de Frutos, A. M., and Casanova, J. L.: Absorption by oxygen and water vapor in the real atmosphere, Appl. Optics, 26, 501-505, https://doi.org/10.1364/AO.26.000501, 1987a. 
Cachorro, V. E., de Frutos, A. M., and Casanova, J. L.: Determination of the Ångström turbidity parameters, Appl. Optics, 26, 3069-3076, https://doi.org/10.1364/AO.26.003069, 1987b.

Cachorro, V. E., Casanova, J. L., and de Frutos, A. M.: The influence of Angström parameters on calculated direct solar spectral irradiances at high turbidity, Sol. Energy, 39, 399-407, https://doi.org/10.1016/S0038-092X(87)80058-0, 1987c.

Cachorro, V. E., González, M. J., de Frutos, A. M., and Casanova, J. L.: Fitting Ångström's formula to spectrally resolved aerosol optical thickness, Atmos. Environ., 1967, 265270, https://doi.org/10.1016/0004-6981(89)90118-2, 1989.

Cachorro, V. E., Durán, P., and de Frutos, A. M.: Retrieval of vertical ozone content using the Chappuis Band with high spectral resolution solar radiation measurements, Geophys. Res. Lett., 23, 3325-3328, https://doi.org/10.1029/96GL03239, 1996.

Cachorro, V. E., Utrillas, M. P., Martinez-Lozano, J. A., and de Frutos, A. M.: A preliminary assessment of a detailed two stream short-wave narrow-band model using spectral radiation measurements, Sol. Energy, 61, 265-273, https://doi.org/10.1016/S0038092X(97)00056-X, 1997.

Cachorro, V. E., Utrillas, P., Vergaz, R., Durán, P., de Frutos, A. M., and Martinez-Lozano, J. A.: Determination of the atmospheric-water-vapor content in the 940-nm absorption band by use of moderate spectral-resolution measurements of direct solar irradiance, Appl. Optics, 37, 4678-4689, https://doi.org/10.1364/AO.37.004678, 1998.

Cachorro, V. E., Durán, P., Vergaz, R., and de Frutos, A. M.: Columnar physical and radiative properties of atmospheric aerosols in north central Spain, J. Geophys. Res.-Atmos., 105, 7161-7175, https://doi.org/10.1029/1999JD901165, 2000a.

Cachorro, V. E., Durán, P., Vergaz, R., and de Frutos, A. M.: Measurements of the atmospheric turbidity of the North-centre continental area in Spain: spectral aerosol optical depth and Ångström turbidity parameters, J. Aerosol Sci., 31, 687-702, https://doi.org/10.1016/S0021-8502(99)00552-2, 2000b.

Cachorro, V. E., Antuña-Sánchez, J. C., and Molina, V.: SSolar_GOA (Source code) (1.0.1), Zenodo [code], https://doi.org/10.5281/zenodo.5796545, 2021.

Carlund, T., Landelius, T., and Josefsson, W.: Comparison and Uncertainty of Aerosol Optical Depth Estimates Derived from Spectral and Broadband Measurements, J. Appl. Meteorol. Clim., 42, 1598-1610, https://doi.org/10.1175/15200450(2003)042<1598:CAUOAO>2.0.CO;2, 2003.

Chandrasekhar, S.: Radiative Transfer, Dover Publication, Inc, New York 10014, ISBN 0-486-60590-6, 1960.

Chiron de la Casinière, A. and Cachorro Revilla, V. E.: La radiación solar en el sistema tierra-atmósfera [translation of French edition "Le Rayonnement solaire dans l'environnement terrestre", Editions Publibook, Paris, France, 2003], Ediciones Universidad de Valladolid, 309 pp., available at repository of University of Valladolid: https://uvadoc.uva.es/ (last access: 18 December 2021.), 2008 (in Spanish).

Dubovik, O., Holben, B. N., Eck, T. F., Smirnov, A., Kaufman, Y. J., King, M. D., Tanré, D., and Slutsker, I.: Variability of absorption and optical properties of key aerosol types observed in worldwide locations, J. Atmos. Sci., 59, 590-608, https://doi.org/10.1175/15200469(2002)059<0590:VOAAOP>2.0.CO;2, 2002.
Durán, P.: "Medidas Espectroradiométricas para la Determinación de Componentes Atmosféricos Ozono, Vapor de Agua y Aerosoles y Modelización del Intercambio Radiativo en la Atmósfera", PhD thesis, University of Valladolid, Valladolid, Spain, 1997.

Egli, L., Gröbner, J., Hülsen, G., Bachmann, L., Blumthaler, M., Dubard, J., Khazova, M., Kift, R., Hoogendijk, K., Serrano, A., Smedley, A., and Vilaplana, J.-M.: Quality assessment of solar UV irradiance measured with array spectroradiometers, Atmos. Meas. Tech., 9, 1553-1567, https://doi.org/10.5194/amt-9-15532016, 2016.

Emde, C., Buras-Schnell, R., Kylling, A., Mayer, B., Gasteiger, J., Hamann, U., Kylling, J., Richter, B., Pause, C., Dowling, T., and Bugliaro, L.: The libRadtran software package for radiative transfer calculations (version 2.0.1), Geosci. Model Dev., 9, 1647-1672, https://doi.org/10.5194/gmd-9-1647-2016, 2016.

Estellés, V., Utrillas, M. P., Martínez-Lozano, J. A., Alcántara, A., Alados-Arboledas, L., Olmo, F. J., Lorente, J., de Cabo, X., Cachorro, V., Horvath, H., Labajo, A., Sorribas, M., Díaz, J. P., Díaz, A. M., Silva, A. M., Elías, T., Pujadas, M., Rodrigues, J. A., Cañada, J., and García, Y.: Intercomparison of spectroradiometers and Sun photometers for the determination of the aerosol optical depth during the VELETA2002 field campaign, J. Geophys. Res.-Atmos., 111, D17207, https://doi.org/10.1029/2005JD006047, 2006.

Fouquart, Y. and Bonnel, B.: Computations of solar heating of the Earth's atmosphere: A new parameterization, Beitr. Phys. Atmos., 53, 35-62, 1980.

García, R. D., Cachorro, V. E., Cuevas, E., Toledano, C., Redondas, A., Blumthaler, M., and Benounna, Y.: Comparison of measured and modelled spectral UV irradiance at Izaña high mountain station: estimation of the underlying effective albedo, Int. J. Climatol., 36, 377-388, https://doi.org/10.1002/joc.4355, 2016.

GOA-UVA Solar Radiation: http://goa.uva.es/solar-radiation/, last access: 30 March 2021.

Goetz, A. F.: Making accurate field spectral reflectance measurements, ASD Inc., Boulder CO USA, 685, 16 pp., 2012.

Goody, R.: Atmospheric Radiation: Theoretical Basis, Oxford Univ, First Edition, Claredon Press, Oxford, London, UK, 436 pp., 1964.

GRAD - Global Radiation and Aerosols: ESRL Global Monitoring Laboratory, https://www.esrl.noaa.gov/gmd/grad/, last access: 19 December 2021.

Gueymard, C.: SMARTS2: a simple model of the atmospheric radiative transfer of sunshine: algorithms and performance assessment, Florida Solar Energy Center, Cocoa, FL, USA, 84 pp., 1995.

Gueymard, C. A.: Parameterized transmittance model for direct beam and circumsolar spectral irradiance, Sol. Energy, 71, 325346, https://doi.org/10.1016/S0038-092X(01)00054-8, 2001.

Gueymard, C. A.: The sun's total and spectral irradiance for solar energy applications and solar radiation models, Sol. Energy, 76 , 423-453, https://doi.org/10.1016/j.solener.2003.08.039, 2004.

Gueymard, C. A.: SMARTS Code, Version 2.9. 5 User's Manual for Windows, Solar Consulting Services, 50 pp., 2005.

Gueymard, C. A.: REST2: High-performance solar radiation model for cloudless-sky irradiance, illuminance, and photosynthetically active radiation - Validation 
with a benchmark dataset, Sol. Energy, 82, 272-285, https://doi.org/10.1016/j.solener.2007.04.008, 2008.

Gueymard, C. A.: The SMARTS spectral irradiance model after 25 years: New developments and validation of reference spectra, Sol. Energy, 187, 233-253, https://doi.org/10.1016/j.solener.2019.05.048, 2019.

Gueymard, C. A. and Myers, D. R.: Validation and Ranking Methodologies for Solar Radiation Models, in: Modeling Solar Radiation at the Earth's Surface: Recent Advances, edited by: Badescu, V., Springer, Berlin, Heidelberg, 479-510, https://doi.org/10.1007/978-3-540-77455-6_20, 2008.

Gueymard, C. A. and Ruiz-Arias, J. A.: Extensive worldwide validation and climate sensitivity analysis of direct irradiance predictions from 1-min global irradiance, Sol. Energy, 128, 1-30, https://doi.org/10.1016/j.solener.2015.10.010, 2016.

Habte, A., Andreas, A., Ottoson, L., Gueymard, C., Fedor, G., Fowler, S., Peterson, J., Naranen, R., Kobashi, T., Akiyama, A., and Takagi, S.: Indoor and Outdoor Spectroradiometer Intercomparison for Spectral Irradiance Measurement, National Renewable Energy Lab. (NREL), Golden, Colorado, USA, https://doi.org/10.2172/1134121, 2014.

Hamill, P., Giordano, M., Ward, C., Giles, D., and Holben, B.: An AERONET-based aerosol classification using Mahalanobis distance, Atmos. Environ., 140, 213-233, https://doi.org/10.1016/j.atmosenv.2016.06.002, 2016.

Hannula, H.-R., Heinilä, K., Böttcher, K., Mattila, O.-P., Salminen, M., and Pulliainen, J.: Laboratory, field, mast-borne and airborne spectral reflectance measurements of boreal landscape during spring, Earth Syst. Sci. Data, 12, 719-740, https://doi.org/10.5194/essd-12-719-2020, 2020.

Hodges, G.: ARM Multi-Filter Rotating Shadowband Radiometer (MFRSR): irradiances, United State, https://doi.org/10.5439/1081481, 1993.

Houghton, J.: The Physics of Atmospheres, Cambridge University Press, 340 pp., 2002.

Jacquemoud, S., Wout Verhoef, W., Baret, F., Bacour, C., and Zarco-Tejada, P. J., Asner, G. P., François, C., and Ustin, S. L.: PROSPECT+SAIL models: A review of use for vegetation characterization, Remote Sens. Environ., 113, S56-S66, https://doi:/10.1016/j.rse.2008.01.026, 2009.

Joseph, J. H., Wiscombe, W. J., and Weinman, J. A.: The Delta-Eddington Approximation for Radiative Flux Transfer, J. Atmos. Sci., 33, 2452-2459, https://doi.org/10.1175/15200469(1976)033<2452:TDEAFR>2.0.CO;2, 1976.

Kasten, F. and Young, A. T.: Revised optical air mass tables and approximation formula, Appl. Optics, 28, 4735, https://doi.org/10.1364/AO.28.004735, 1989.

Kiedron, P. W., Michalsky, J. J., Berndt, J. L., and Harrison, L. C.: Comparison of spectral irradiance standards used to calibrate shortwave radiometers and spectroradiometers, Appl. Optics, 38, 2432-2439, https://doi.org/10.1364/AO.38.002432, 1999.

King, M. D. and Harshvardhan: Comparative Accuracy of Selected Multiple Scattering Approximations, J. Atmos. Sci., 43, 784-801, https://doi.org/10.1175/15200469(1986)043<0784:CAOSMS>2.0.CO;2, 1986.

Kneizys, F. X.: Users Guide to Lowtran 7, Air Force Geophysics Laboratory, United States Air Force, 148 pp., 1988.
Koepke, P. and Quenzel, H.: Water vapor: spectral transmission at wavelengths between $0.7 \mu \mathrm{m}$ and $1 \mu \mathrm{m}$, Appl. Optics, 17, 2114 2118, https://doi.org/10.1364/AO.17.002114, 1978.

Kokhanovsky, A. A.: Aerosol Optics: Light Absorption and Scattering by Particles in the Atmosphere, Springer Science \& Business Media, 154 pp., https://doi.org/10.1007/978-3-540-49909$1,2008$.

Komhyr, W. D.: Operations Handbook - Ozone Observations with a Dobson Spectrophotometer, WMO, 91 pp., 1980.

Kondratyev, K. Y. A.: Radiation in the atmosphere, edited by: Van Mieghem, J., International Geophysics Series, vol. 12, Academic Press, New York and London, 1969.

Kurucz, R.: Synthetic infrared spectra, Proceeding of the 154th Symposium of the International Astronomical Union (IAU), 523 pp., Tucson, Arizona (USA), March 2-6, 1992. Infrared Solar Physics, edited by: Rabin, D. M., Jefferies, J. T. and Linsey, C., Kluwer Academic Publishers, ISBN 978-0-7923-2523-9, https://doi.org/10.1007/978-94-011-1926-9, 1992.

Leckner, B.: The spectral distribution of solar radiation at the earth's surface - elements of a model, Sol. Energy, 20, 143-150, https://doi.org/10.1016/0038-092X(78)90187-1, 1978.

Lenoble, J.: Radiative Transfer in Scattering and Absorbing Atmospheres: Standard Computational Procedures, A. Deepak Pub., Hampton, Va, USA, 300 pp., 1985.

Lenoble, J.: Atmospheric Radiative Transfer, A. Deepak Pub., Hampton, Va., USA, 532 pp., 1993.

Lenoble, J.: Modeling of the influence of snow reflectance on ultraviolet irradiance for cloudless sky, Appl. Optics, 37, 2441-2447, https://doi.org/10.1364/AO.37.002441, 1998.

libRadtran user's guide 2015 - Mayer, B., Killing A., Emde, C., Buras R., Hamann U., Gasteiger J., and Richter B.: Edition for libRadtran version 2, http://www.libradtran.org/doc/libRadtran. pdf (last access: 19 September 2021), 24 August 2015.

libRadtran user's guide 2020 - Mayer, B., Killing A., Emde, C., Buras R., Hamann U., Gasteiger J., and Richter B.: Edition for libRadtran version 2.04, http://www.libradtran.org/doc/ libRadtran.pdf (last access: 19 September 2021), 24 December 2020.

LI-COR: LI-1800 Portable spectroradiomer Instruction Manual, Lincoln, Nebraska, USA, 149 pp., https://www.licor.com/env/ support/LI-1800/home.html (last access: 12 April 2021), 1989.

Lin, H., Zhang, F., Wu, K., and Xu, J.: Comparisons of $\delta$-Two-Stream and $\delta$-Four-Stream Radiative Transfer Schemes in RRTMG for Solar Spectra, SOLA, 15, 87-93, https://doi.org/10.2151/sola.2019-017, 2019.

Liou, K.-N.: Radiation and Cloud Processes in the Atmosphere: Theory, Observation and Modeling, 1st Edn, Oxford University Press, New York, NY, USA, 504 pp., 1992.

Liou, K. N.: An Introduction to Atmospheric Radiation, Elsevier, 598 pp., 2002.

Martínez-Lozano, J. A., Utrillas, M. P., Tena, F., and Cachorro, V. E.: The parameterisation of the atmospheric aerosol optical depth using the Ångström power law, Sol. Energy, 63, 303-311, https://doi.org/10.1016/S0038-092X(98)00077-2, 1998.

Martínez-Lozano, J. A., Utrillas, M. P., Pedrós, R., Tena, F., Díaz, J. P., Expósito, F. J., Lorente, J., Cabo, X. de, Cachorro, V., Vergaz, R., and Carreño, V.: Intercomparison of Spectroradiometers for Global and Direct Solar Irradiance in 
the Visible Range, J. Atmos. Ocean. Tech., 20, 997-1010, https://doi.org/10.1175/1457.1, 2003.

Mayer, B. and Kylling, A.: Technical note: The libRadtran software package for radiative transfer calculations - description and examples of use, Atmos. Chem. Phys., 5, 1855-1877, https://doi.org/10.5194/acp-5-1855-2005, 2005.

Meador, W. E. and Weaver, W. R.: Two-Stream Approximations to Radiative Transfer in Planetary Atmospheres: A Unified Description of Existing Methods and a New Improvement, J. Atmos. Sci., 37, 630-643, https://doi.org/10.1175/15200469(1980)037<0630:TSATRT>2.0.CO;2, 1980.

Michalsky, J. J., Anderson, G. P., Barnard, J., Delamere, J., Gueymard, C., Kato, S., Kiedron, P., McComiskey, A., and Ricchiazzi, P.: Shortwave radiative closure studies for clear skies during the Atmospheric Radiation Measurement 2003 Aerosol Intensive Observation Period, J. Geophys. Res.-Atmos., 111, D14S90, https://doi.org/10.1029/2005JD006341, 2006.

Milton, E. J., Schaepman, M. E., Anderson, K., Kneubühler, M., and Fox, N.: Progress in field spectroscopy, Remote Sens. Environ., 113, S92-S109, https://doi.org/10.1016/j.rse.2007.08.001, 2009.

Mlawer, E. J. and Turner, D. D.: Spectral Radiation Measurements and Analysis in the ARM Program, Meteorol. Monogr., 57, 14.1-14.17, https://doi.org/10.1175/AMSMONOGRAPHSD-15-0027.1, 2016.

Mlawer, E. J., Brown, P. D., Clough, S. A., Harrison, L. C., Michalsky, J. J., Kiedron, P. W., and Shippert, T.: Comparison of spectral direct and diffuse solar irradiance measurements and calculations for cloud-free conditions, Geophys. Res. Lett., 27, 2653-2656, https://doi.org/10.1029/2000GL011498, 2000.

Nikoghossian, A. G.: Ambartsumian's invariance principle and some nonlinear relations in radiative transfer theory, Astrophysics, 52, 431-439, https://doi.org/10.1007/s10511-009-9079z, 2009.

Norton, M., Amillo, A. M. G., and Galleano, R.: Comparison of solar spectral irradiance measurements using the average photon energy parameter, Sol. Energy, 120, 337-344, https://doi.org/10.1016/j.solener.2015.06.023, 2015.

NREL Spectral Solar Radiation Data Base: https://www.nrel.gov/ grid/solar-resource/spectral-solar.html, last access: 30 March 2021.

NSRDB NREL: https://nsrdb.nrel.gov/, last access: 30 March 2021. Orphal, J., Staehelin, J., Tamminen, J., Braathen, G., De Backer, M.-R., Bais, A., Balis, D., Barbe, A., Bhartia, P. K., Birk, M., Burkholder, J. B., Chance, K., von Clarmann, T., Cox, A., Degenstein, D., Evans, R., Flaud, J.-M., Flittner, D., GodinBeekmann, S., Gorshelev, V., Gratien, A., Hare, E., Janssen, C., Kyrölä, E., McElroy, T., McPeters, R., Pastel, M., Petersen, M., Petropavlovskikh, I., Picquet-Varrault, B., Pitts, M., Labow, G., Rotger-Languereau, M., Leblanc, T., Lerot, C., Liu, X., Moussay, P., Redondas, A., Van Roozendael, M., Sander, S. P., Schneider, M., Serdyuchenko, A., Veefkind, P., Viallon, J., Viatte, C., Wagner, G., Weber, M., Wielgosz, R. I., and Zehner, C.: Absorption cross-sections of ozone in the ultraviolet and visible spectral regions: Status report 2015, J. Mol. Spectrosc., 327, 105-121, https://doi.org/10.1016/j.jms.2016.07.007, 2016.

Pierluissi, J. H. and Maragoudakis, C. E.: Molecular transmittance band model for oxygen in the infrared, Appl. Optics, 25, 1538, https://doi.org/10.1364/AO.25.001538, 1986.
Pierluissi, J. H. and Tsai, C.-M.: New LOWTRAN models for the uniformly mixed gases, Appl. Optics, 26, 616, https://doi.org/10.1364/AO.26.000616, 1987.

Pierluissi, J. H., Maragoudakis, C. E., and Tehrani-Movahed, R.: New LOWTRAN band model for water vapor, Appl. Optics, 28, 3792-3795, https://doi.org/10.1364/AO.28.003792, 1989.

Räisänen, P.: Two-stream approximations revisited: A new improvement and tests with GCM data, Q. J. Roy. Meteor. Soc., 128, 2397-2416, https://doi.org/10.1256/qj.01.161, 2002.

Rapp-Arrarás, Í. and Domingo-Santos, J. M.: Extinction, refraction, and delay in the atmosphere, J. Geophys. Res.-Atmos., 113, D20116, https://doi.org/10.1029/2008JD010176, 2008.

Redondas, A., Evans, R., Stuebi, R., Köhler, U., and Weber, M.: Evaluation of the use of five laboratory-determined ozone absorption cross sections in Brewer and Dobson retrieval algorithms, Atmos. Chem. Phys., 14, 1635-1648, https://doi.org/10.5194/acp-14-1635-2014, 2014.

Riordan, C., Myers, D., Rymes, M., Hulstrom, R., Marion, W., Jennings, C., and Whitaker, C.: Spectral solar radiation data base at SERI, Sol. Energy, 42, 67-79, https://doi.org/10.1016/0038092X(89)90131-X, 1989.

Ruiz-Arias, J. A. and Gueymard, C. A.: Worldwide intercomparison of clear-sky solar radiation models: Consensusbased review of direct and global irradiance components simulated at the earth surface, Sol. Energy, 168, 10-29, https://doi.org/10.1016/j.solener.2018.02.008, 2018.

Sengupta, M., Xie, Y., Lopez, A., Habte, A., Maclaurin, G., and Shelby, J.: The National Solar Radiation Data Base (NSRDB), Renew. Sust. Energ. Rev., 89, 51-60, https://doi.org/10.1016/j.rser.2018.03.003, 2018.

Sobolev, V. V.: A Treatise on Radiative Transfer, edited by: Van Nostrand, D., Princeton, NJ, USA, 1963.

Sukhodolov, T., Rozanov, E., Shapiro, A. I., Anet, J., Cagnazzo, C., Peter, T., and Schmutz, W.: Evaluation of the ECHAM family radiation codes performance in the representation of the solar signal, Geosci. Model Dev., 7, 2859-2866, https://doi.org/10.5194/gmd-7-2859-2014, 2014.

Tanré, D., Deroo, C., Duhaut, P., Herman, M., Morcrette, J. J., Perbos, J., and Deshamps, P. Y.: Simulation of the Satellite Signal in the Solar Spectrum (5S), Laboratoire d'Optique Atmosphérique, Université des Sciences et Techniques de Lille, Villeneuve d'Asq, France, 1986.

Teillet, P. M.: Rayleigh optical depth comparisons from various sources, Appl. Optics, 29, 1897-1900, https://doi.org/10.1364/AO.29.001897, 1990.

Toledano, C., Cachorro, V., Berjön, A., Sorribas, M., Vergaz, R., Frutos, Á. D., Antón, M., and Gausa, M.: Aerosol optical depth at ALOMAR Observatory (Andøya, Norway) in summer 2002 and 2003, Tellus B, 58, 218-228, https://doi.org/10.1111/j.16000889.2006.00184.x, 2006.

Tomasi, C., Vitake, V., and De Santis, L. V.: Relative optical mass functions for air, water vapour, ozone and nitrogen dioxide in atmospheric models presenting different latitudinal and seasonal conditions, Meteorol. Atmos. Phys., 65, 11-30, https://doi.org/10.1007/BF01030266, 1998.

Tomasi, C., Vitale, V., Petkov, B., Lupi, A., and Cacciari, A.: Improved algorithm for calculations of Rayleigh-scattering optical depth in standard atmospheres, Appl. Optics, 44, 3320-3341, https://doi.org/10.1364/AO.44.003320, 2005. 
Utrillas, M. P., Boscá, J. V., Martı̀̀nez-Lozano, J. A., Cañada, J., Tena, F., and Pinazo, J. M.: A comparative study of SPCTRAL2 and SMARTS2 parameterised models based on spectral irradiance measurements at Valencia, Spain, Sol. Energy, 63, 161-171, https://doi.org/10.1016/S0038-092X(98)00058-9, 1998.

Utrillas, M. P., Martínez-Lozano, J. A., Cachorro, V. E., Tena, F., and Hernandez, S.: Comparison of aerosol optical thickness retrieval from spectroradiometer measurements and from two radiative transfer models, Sol. Energy, 68, 197-205, https://doi.org/10.1016/S0038-092X(99)00060-2, 2000.

Vergaz, R.: "Propiedades ópticas de los aerosoles atmosféricos. Caracterización del área del Golfo de Cádiz”, PhD thesis, University of Valladolid, Valladolid, Spain, 2001.

Vergaz, R., Cachorro, V. E., de Frutos, A. M., Vilaplana, J. M., and Morena, B. A.: Columnar characteristics of aerosols by spectroradiometer measurements in the maritime area of the Cadiz Gulf (Spain), Int. J. Climatol., 25, 1781-1804, https://doi.org/10.1002/joc.1208, 2005.

Vermote, E. and Tanré, D.: Analytical expressions for radiative properties of planar Rayleigh scattering media, including polarization contributions. J. Quant. Spectrosc. Radiat. Tranfer, 41, 305-314, https://doi.org/10.1016/0022-4073(92)90149-X, 1992.

Wehrli, C.: Extraterrestrial solar spectrum, Publication number 615. Physikalisch-Meteorologisches Observatorium and World Radiation Center (PMO/WRC), Davos, Switzerland, 1985.

Wild, M.: Global dimming and brightening: A review, J. Geophys. Res.-Atmos., 114, D00D16, https://doi.org/10.1029/2008JD011470, 2009.
Wild, M., Folini, D., Schär, C., Loeb, N., Dutton, E. G., and König-Langlo, G.: The global energy balance from a surface perspective, Clim. Dynam., 40, 3107-3134, https://doi.org/10.1007/s00382-012-1569-8, 2013.

WOUDC, World Ozone and Ultraviolet Radiation Data Center: https://woudc.org/archive/Summaries/Spectral_UV/, last access: 30 March 2021.

Xie, Y. and Sengupta, M.: A Fast All-sky Radiation Model for Solar applications with Narrowband Irradiances on Tilted surfaces (FARMS-NIT): Part I. The clear-sky model, Sol. Energy, 174, 691-701, https://doi.org/10.1016/j.solener.2018.09.056, 2018.

Yang, D. and Boland, J.: Satellite-augmented diffuse solar radiation separation models, J. Renew. Sustain. Ener., 11, 023705, https://doi.org/10.1063/1.5087463, 2019.

Yang, P., Prikaziuk, E., Verhoef, W., and van der Tol, C.: SCOPE 2.0: a model to simulate vegetated land surface fluxes and satellite signals, Geosci. Model Dev., 14, 4697-4712, https://doi.org/10.5194/gmd-14-4697-2021, 2021.

Zdunkowski, W., Welch, R. M., and Kork, G.: An investigation of the structure of typical two-stream methods for the calculation of solar fluxes and heating rates in clouds, Beitr. Phys. Atmos., 53, 147-166, 1980.

Zdunkowski, W., Trautmann, T., and Bott, A.: Radiation in the Atmosphere: A Course in Theoretical Meteorology, Cambridge University Press, 497 pp., 2007. 